NBER WORKING PAPER SERIES

\title{
ENDOGENOUS EXCHANGE RATE PASS-THROUGH WHEN NOMINAL PRICES ARE SET IN ADVANCE
}

\author{
Michael B. Devereux \\ Charles Engel \\ Peter E. Storgaard \\ Working Paper 9543 \\ http://www.nber.org/papers/w9543 \\ NATIONAL BUREAU OF ECONOMIC RESEARCH \\ 1050 Massachusetts Avenue \\ Cambridge, MA 02138 \\ March 2003
}

This paper is a combination and comprehensive revision of Devereux and Engel (2001), and Storgaard (2001). We thank Philippe Bacchetta, Paul Beaudry, Paul Bergin, Menzie Chinn, Linda Goldberg, Luisa Lambertini, Aaron Tornell, Eric van Wincoop, Carlos Vegh, Jaume Ventura, and participants of seminars at the New York Federal Reserve Bank, University of British Columbia, University of Santa Cruz, and University of California at Los Angeles, and two referees for comments. We thank Shiu-Sheng Chen and Akito Matsumoto for excellent research assistance. The views expressed are those of the authors and not necessarily those of Danmarks Nationalbank. Engel acknowledges support from the NSF through a grant to University of Wisconsin. The views expressed herein are those of the authors and not necessarily those of the National Bureau of Economic Research.

(C)2003 by Michael B. Devereux, Charles Engel, and Peter E. Storgaard. All rights reserved. Short sections of text not to exceed two paragraphs, may be quoted without explicit permission provided that full credit including Cnotice, is given to the source. 
Endogenous Exchange Rate Pass-through when Nominal Prices are Set in Advance

Michael B. Devereux, Charles Engel, and Peter E. Storgaard

NBER Working Paper No. 9543

March 2003

JEL No. F3, F4

\section{$\underline{\text { ABSTRACT }}$}

This paper develops a model of endogenous exchange rate pass through within an open economy macroeconomic framework, where both pass-through and the exchange rate are simultaneously determined, and interact with one another. Pass-through is endogenous because firms choose the currency in which they set their export prices. There is a unique equilibrium rate of pass-through under the condition that exchange rate volatility rises as the degree of pass-through falls. We show that the relationship between exchange rate volatility and economic structure may be substantially affected by the presence of endogenous pass-through. Our key results show that pass-through is related to the relative stability of monetary policy. Countries with relatively low volatility of money growth will have relatively low rates of exchange rate pass-through, while countries with relatively high volatility of money growth will have relatively high pass-through rates.

Michael B. Devereux University of British Columbia and CEPR devm@interchange.ubc.ca

Peter E. Storgaard Danmarks Nationalbank pso@nationalbanken.dk
Charles Engel

Department of Economics

University of Wisconsin

1180 Observatory Drive

Madison, WI 53706-1393

and NBER

cengel@ssc.wisc.edu 


\section{Introduction}

A large body of empirical evidence has found that pass-through of exchange rate changes to import prices is less than complete. ${ }^{\square}$ However, the degree of pass-through is not uniform across countries or industries. ${ }^{2}$ Exchange rate pass-through matters for many questions; for instance the predicted volatility of the real exchange rate, the international transmission of macroeconomic shocks, and the welfare benefits of international policy coordination. It $_{\text {It }}$ is therefore important to understand the underlying determinants of pass-through. While there is a large literature that has examined long-run pass-through - the optimal pricing choice of firms when markets are segmented and competition is imperfect - considerably less study has been undertaken of pass-through in the short run when there may be some nominal price stickiness.

We analyze the determinants of an exporting firm's choice of currency in which to pre-set prices. With nominal price stickiness, the aggregate degree of exchange rate pass-through is determined by this decision. The paper therefore develops a model of endogenous exchange rate pass-through, in a framework in which the exchange rate itself is endogenously determined. We find that there is a twoway interaction between exchange rate pass-through and exchange rate volatility. Exchange rate volatility determines the price-setting choices of a firm, and therefore the degree of aggregate exchange rate pass-through. But in turn, the degree of exchange rate pass-through itself determines the volatility of the exchange rate.

The starting point of our analysis is the assumption that prices are sticky in the short run. There is a long tradition of nominal price stickiness in models of macroeconomics. But in an open economy, the question of price stickiness is more problematic. Clearly, the exchange rate is not sticky. As a result, when a good is traded between countries with flexible exchange rates, the currency in which the price of the good is fixed becomes an important factor in determining the effect of exchange rate changes. If

\footnotetext{
${ }^{1}$ A short list of citations includes Krugman (1987), Knetter (1989, 1993), Feenstra (1989), Feenstra, Gagnon, and Knetter (1996), Goldberg and Knetter (1997), Goldberg (1995), and Goldberg and Verboven (2001) for studies of pass-through to import prices. Engel (1993), Engel and Rogers (1996) and Parsley and Wei (2001), among many others, have studied pass-through to consumer prices.

2 This point was emphasized in the survey of Goldberg and Knetter (1997).
} 
prices are sticky in the currency of the exporter (we denote this as PCP, or 'producer currency pricing'), then pass-through from exchange rate changes to final consumers will be complete, and imported goods will display considerable price flexibility. On the other hand, if goods prices are fixed in consumer's currency (LCP, or 'local currency pricing'), there is no pass-through at all, and imported goods prices are unaffected by exchange rate changes.

When a firm sells abroad, would it prefer to follow PCP or LCP? This question has been addressed before, but mostly in partial equilibrium settings, which take as exogenous key variables that are influenced by the price-setting configuration itself. For instance, in general equilibrium, the behavior of exchange rates, labor costs, and demand may themselves depend on how prices are set.

Our analysis proceeds in three stages. In the first stage, we examine the choice of currency of price setting for a firm that has local market power in a stochastic environment, taking as given the distribution of exchanges rates, market demand, and prices of other firms. We establish a very simple rule for the choice of price-setting currency. If a firm is choosing its prices optimally, then up to a second order approximation, its decision depends only on the variance of the exchange rate and the covariance of the exchange rate with marginal costs. The higher is the variance of the exchange rate, the more incentive the firm has to set prices in its own currency. The higher is the covariance of the exchange rate and marginal costs, the more the firm would wish to set its price in foreign currency. A remarkable aspect of the result is that the currency of pricing decision is independent of the variance of market demand and the prices of all other firms.

We then place the firm in a two-country intertemporal general equilibrium environment where the exchange rate and marginal costs are determined by random money shocks. Each country has a continuum of firms that export goods to the other country. The degree of exchange rate pass-through is determined by the measure of firms that choose to follow PCP. While firms' decisions with respect to currency of pricing depend on the distribution of exchange rates and marginal costs, these distributions in

\footnotetext{
${ }^{3}$ See for example, Betts and Devereux (1996, 2000), Devereux and Engel (2000), Tille (2000), and Lane (2001).
} 
turn depend on the degree of aggregate exchange rate pass-through. There is a two way inter-relationship between exchange rate volatility and exchange rate pass-through.

Is there a unique equilibrium degree of exchange rate pass-through? If pass-through depends on exchange rate volatility, and exchange rate volatility depends on pass-through, there arises the possibility of multiple equilibria. 9 Roughly speaking, the condition for a unique equilibrium is that exchange rate volatility is higher in an economy where exchange rate pass-through is lower. On the other hand, if declining pass-through is associated with a decline in exchange rate volatility, then multiple equilibria may exist. We show that in our model, multiple equilibria are unlikely to occur.

The overall degree of exchange rate pass-through depends on various structural features of the economy. Pass-through is higher the more stable are marginal costs in each country, and the lower is the elasticity of substitution between domestic and foreign goods. Moreover, in an environment of endogenous exchange rate pass-through, conventional results on the determinants of exchange rate volatility must be applied with caution. In particular, our model of exchange rate determination implies that low exchange rate pass-through can produce substantial exchange rate volatility. But when passthrough is endogenous, the presence of high exchange rate volatility will itself increase the incentive for firms to follow PCP. By increasing the rate of aggregate pass-through, this dampens exchange rate volatility.

In the third stage of our analysis, we examine the relationship between monetary policy and passthrough. Our key results relate to the impact of differential monetary shocks on the degree of exchange pass-through. When countries have differences in the volatility of money growth, our model predicts that exporting firms in both countries will tend to pre-set their prices in the country that has the more stable money growth. This leads to an important link between monetary policy and price stability. A country that follows a successful policy of monetary stabilization, reducing the variance of its money growth, will experience a price-stability 'bonus'. This is because foreign exporters will begin more and more to set

\footnotetext{
${ }^{4}$ This was pointed out by Devereux and Engel (2001). A slightly different perspective on multiple equilibria in the decision over invoicing currency is presented by Bacchetta and Van Wincoop (2002). We discuss Bacchetta and Van Wincoop (2002) more fully below.
} 
their prices in that country's currency, thereby reducing the impact of exchange rate changes on the country's CPI. But the flip side of this is that the foreign country experiences less stable prices, since exporters in the stabilizing country will also begin to pre-set their prices in domestic currency. Thus, there is a 'beggar-thy-neighbor' aspect to policies of monetary stabilization in an environment of endogenous pass-through.

This paper is part of a wider literature on sticky price open economy macroeconomic models. Recently, several studies have looked at the determination of the degree of exchange rate pass-through in general equilibrium models with endogenous exchange rates. Devereux and Engel (2001) and Storgaard (2001) present a very similar analysis of the decision with respect to PCP versus LCP, in separate works that have been combined to form the present paper. Bacchetta and Van Wincoop (2001) present numerical results on equilibrium pass-through in a static environment. They find a positive connection between risk-aversion and local currency pricing. In some cases they find that there are no pure strategy equilibria for firms' pricing decisions, a theme we take up below. Bacchetta and Van Wincoop (2002) focus on the choice of invoicing currency (or currency of price setting) in a static general equilibrium framework, providing analytical results. Their partial equilibrium results take on much of the flavor of theoretical conclusions of Feenstra, Gagnon, and Knetter's (1996) - that pass-through is greater when exporting firms have a high degree of market power. They emphasize the possibility of multiple equilibria that arise because of strategic complementarities between the price-setting decisions of firms. They also explore the role of multiple countries, and the impact of a monetary union on the equilibrium invoicing currency in international trade. In their paper, multiple equilibria arise due to diminishing returns to scale in a manner that is absent in our work. But they do not focus on the two-way interaction between exchange rate pass-through and exchange rate volatility, nor do they examine the implication of differences in monetary policies across countries.

The next section sets out the problem of a single firm in a stochastic environment, and establishes a simple rule for the determination of the currency of pricing. Section 2 sets out the general equilibrium 
model. Section 3 combines section 1 and section 2 to determine the degree of exchange rate passthrough. Section 4 explores the implications of differences in the variance of money growth among countries.

\section{Section 1. The Decision of a Firm in a Stochastic Environment}

In this section, we examine the choice of currency of price setting for a monopolistic exporting firm in a partial equilibrium setting. We develop a condition on variables (exchange rates and wages) that are exogenous to the firm, under which the firm will choose to price in its own currency or the currency of the importing country. In the next section, we explore the properties of a specific macroeconomic model. Embedded in that model are firms that face precisely the same type of demand curve and cost function as does the firm in this section.

Take a firm $i$ in the home country selling a differentiated good to a foreign market. Assume that the firm faces the CES demand curve

$$
Y(P(i))=\left(\frac{P(i)}{P}\right)^{-\lambda}\left(\frac{P}{P^{*}}\right)^{-\theta} Y^{*}, \quad \lambda>1
$$

$P(i)$ is the price the foreign consumer pays for good $i . P$ is the price index for all home goods purchased by the foreign consumer, and $P^{*}$ is the foreign country consumer price index. Without loss of generality let $P(i), P$, and $P^{*}$ be denominated in foreign currency. $Y^{*}$ is a demand shift variable that is independent of price. $\lambda$ is the price elasticity of demand facing the domestic firm $i . \theta$ is the foreign price elasticity of demand for domestic goods. Firm $i$ is a small enough supplier that it ignores the impact of its pricing decision on $P$.

Equation (1.1) imposes a particular functional form on the firm's demand schedule so as to be consistent with the general equilibrium model developed below. But we make no specific assumptions

\footnotetext{
${ }^{5}$ See Obstfeld and Rogoff (1995, 1998, 2000), Lane (2001), Bacchetta and Van Wincoop (2000), Devereux and Engel (2001), and many others.
} 
about the distribution of $P, P^{*}$, and $Y^{*}$. These variables may be stochastic, and may be correlated with the exchange rate.

The firm has a constant returns to scale production function, and faces the (possibly stochastic) marginal cost $W$. The firm evaluates profits using the (stochastic) discount factor $d$. In the model below, we determine the exact form of $d$.

\section{PCP versus LCP}

The firm has to decide whether to set its price in domestic or foreign currency. Whatever currency it chooses, it must set the price before the state of the world is known.

If firm $i$ sets its price in its own currency, (PCP), then expected discounted profits are

$$
E \Pi^{P C P}=E\left[d\left(P^{P C P}(i)-W\right)\left(\frac{P^{P C P}(i)}{S P}\right)^{-\lambda}\left(\frac{P}{P^{*}}\right)^{-\theta} Y^{*}\right],
$$

where $S$ is the exchange rate (domestic-currency price of foreign currency).

If the firm sets its price in the foreign currency (LCP), then expected discounted profits are

$$
E \Pi^{L C P}=E\left[d\left(S P^{L C P}(i)-W\right)\left(\frac{P^{L C P}(i)}{P}\right)^{-\lambda}\left(\frac{P}{P^{*}}\right)^{-\theta} Y^{*}\right] .
$$

We shall see in Proposition 1 (below) that the optimal currency of price setting does not depend on the characteristics of the discount factor, $d$. The only restriction we impose is that the discount factor is exogenous to the firm. In the macroeconomic model we present below, the discount factor is specified so that firms are maximizing the expected utility of firm owners. Nominal profits are deflated by the exact consumption price index of the representative firm owner, and weighted by the marginal utility of consumption of firm owners. However, our results (Proposition 1) are more general and hold irrespective of how firm managers evaluate the marginal value of future nominal income to firm owners.

The profit-maximizing price for the firm, under PCP and LCP, respectively, may easily be derived as follows:

$$
P^{P C P}(i)=\frac{\lambda}{\lambda-1} \frac{E\left(W S^{\lambda} Z\right)}{E\left(S^{\lambda} Z\right)}, \quad P^{L C P}(i)=\frac{\lambda}{\lambda-1} \frac{E(W Z)}{E(S Z)}
$$


where $Z=d P^{\lambda-\theta} P^{* \theta} Y^{*}$.

Using these solutions, the expressions for expected discounted profits are:

$$
\begin{aligned}
& E \Pi^{P C P}=\tilde{\lambda}\left[E\left(S^{\lambda} Z\right)\right]^{\lambda}\left[E\left(S^{\lambda} Z W\right)\right]^{1-\lambda} \\
& E \Pi^{L C P}=\tilde{\lambda}[E(S Z)]^{\lambda}[E(Z W)]^{1-\lambda}
\end{aligned}
$$

where $\tilde{\lambda}=\frac{1}{\lambda-1}\left(\frac{\lambda}{\lambda-1}\right)^{-\lambda}$. From expressions (1.4) and (1.5), we may establish:

\section{Proposition 1}

The home firm sets its price for the foreign market in home (foreign) currency if

$$
\left[\frac{\operatorname{var}(s)}{2}-\operatorname{cov}(w, s)\right]>0,(<0)
$$

where $s=\ln (S)$, and $w=\ln (W)$. Proof: see appendix A.

This condition says that $(\log )$ exchange rate variance leads the firm to set its price in terms of home currency. But a positive covariance between (the log of) the exchange rate and (the log of) marginal costs leads the firm to set its price in foreign currency. To explain this condition, take expressions (1.2) and (1.3) again. In any given state of the world, under either pricing policy, profits are increasing in the exchange rate. Under PCP, a rise in the exchange rate will increase demand for the firm's good, holding other firms' prices constant. Under LCP, a rise in the exchange rate will increase the home currency value of sales. But under PCP, the profit function in any state of the world is strictly convex in the exchange rate, for $\lambda>1$, while with LCP the profit function is linear in the exchange rate. This means that, holding other variables constant, an increase in exchange rate variance increases profits under PCP relative to LCP. If this were the only consideration, the firm would follow PCP if there were any exchange rate uncertainty.

But there is a secondary channel, arising from the uncertainty of marginal costs. If the covariance between the exchange rate and marginal cost is positive, this tends to increase expected total costs under 
PCP, since the firm's demand is higher precisely when the cost of production is higher. ${ }^{6}$ Under LCP however, demand is independent of the exchange rate (holding other variables constant), so that expected total costs do not depend on the covariance between the exchange rate and marginal cost. This channel therefore increases the incentive to choose LCP.

When we add both of these channels together, we arrive at exactly the condition described in the proposition. Note a striking feature of Proposition 1. The condition does not depend on the variance of $Z$ (which itself depends on total demand, the prices of other home firms, the foreign CPI, and the stochastic discount factor), or the covariance of $Z$ with $S$ or $W$. It follows that Proposition 1 holds in any environment in which the firm's demand schedule can be described by (1.1). In particular, it will apply in the same form for the general equilibrium model that we construct below. Thus, given $\operatorname{var}(s)$ and $\operatorname{cov}(w, s)$, the firm's optimal currency of pricing is independent of the pricing policies of other firms, the assumptions about international financial markets, or the characteristics of any other macro variables in the domestic or foreign economies.

Why does the condition in proposition 1 not depend on the distribution of $Z$ ? Rewrite (1.2) and (1.3) as:

$$
\begin{aligned}
& E \Pi^{P C P}=E\left(X_{1} Z\right), \text { where } X_{1}=\left(P^{P C P}(i)-W\right)\left(\frac{P^{P C P}(i)}{S}\right)^{-\lambda} \\
& E \Pi^{L C P}=E\left(X_{2} Z\right), \text { where } X_{2}=\left(S P^{L C P}(i)-W\right)\left(P^{L C P}(i)\right)^{-\lambda}
\end{aligned}
$$

An increase in $S$ increases both $X_{1}$ and $X_{2}$, so in both the PCP and LCP cases, expected profits are higher when the covariance of $S$ and $Z$ is positive. In the PCP case, when there is a depreciation, profits increase because demand for the good increases. In the LCP case, as $S$ rises, profits increase because the

\footnotetext{
${ }^{6}$ There is a link between the conditions for pricing in consumer's currency and the conditions for low pass-through when prices are set ex post. We have noted the similarity between the conditions in Bachetta and van Wincoop's (2002) model, and Feenstra, Gagnon, and Knetter's (1996) model of pricing to market. Friberg (1998) draws a link between Giovannini's (1988) model of choice of currency for setting prices and models of pricing to market such as Krugman's (1987). Here we note that the pricing to market literature - especially the empirical literature - has drawn the link between correlation of wages with exchange rates, and the response of import prices to exchange rate changes. See Goldberg and Knetter (1997, p. 1251) for a discussion.
} 
profit margin on each unit rises. Intuitively, the reason why the comovements of $S$ and $Z$ have approximately no effect on the comparison of expected profits in the LCP and PCP cases is that a small deviation in $S$ (around the point of approximation) has equal effects on $X_{1}$ and $X_{2}$. That can be understood by recognizing that under certainty, firms increase prices until the point where the increase in total revenue from raising the price on each unit is equal to the loss in revenue from the lost demand as price increases.

The situation of a foreign firm exporting to the domestic market is entirely analogous, so long as demand can be described as in equation (1). Thus we may state:

\section{Corollary to Proposition 1.}

The foreign firm sets its price for the home market in foreign (home) currency if

$$
\left[\frac{\operatorname{var}(s)}{2}+\operatorname{cov}\left(w^{*}, s\right)\right]>0,(<0) .
$$

\section{Section 2. The General Equilibrium Model}

While the last section examines the decision on currency of pricing taking as given the distribution of the exchange rate, in this section we construct a general equilibrium model of exchange rate determination, taking as given the currency of pricing followed by firms. The model is taken entirely from the recent literature on monopolistic competition in (open economy) macroeconomics (e.g. Blanchard and Kiyotaki 1987, Obstfeld and Rogoff 1995), so our description is kept brief. (The full details of the model are given in the Mathematical Appendix. There are two countries, home and foreign,

7 It is clear from inspection of (1.6) and (1.7) that the mean and variance of $Z$ and the covariance of $Z$ with $W$ affect expected profits equally in the PCP and LCP cases.

${ }^{8}$ How does the condition of proposition 1 relate to the partial equilibrium models of Giovannini (1988) (see also Friberg (1998))? In Giovannini (1988), it is assumed that the exchange rate is the only source of uncertainty in the firm's pricing problem. He then shows that if profits under PCP are concave (convex) in the exchange rate, then LCP (PCP) is preferred to PCP (LCP) by the firm. Profits are concave (convex) in the exchange rate if the market demand curve is concave (convex). In our analysis, holding marginal cost constant, profits must be convex in the exchange rate, because we use a CES demand system in which the demand schedule is convex by construction. Therefore, were the exchange rate the only source of uncertainty, all firms would wish to follow PCP (as we have shown). But our interest is in analyzing the two-way interaction between exchange rate pass-through and exchange rate determination. Since the exchange rate and marginal costs are both driven by the underlying aggregate shocks to the economy, we cannot assume that marginal costs are constant. Hence the condition underlying proposition 1. 
with consumers, firms and governments in each country. There are $n$ households and firms in the home country, and 1- $n$ in the foreign country. All firms have a monopoly over sales of their good, and all workers (households) have a monopoly in setting their wage.

\section{Preferences and Market Structure}

Each consumer $k$ in the home country maximizes expected lifetime utility

$$
U_{t}(k)=E_{t}\left(\sum_{s=t}^{\infty} \beta^{s-t} u_{s}(k)\right), \quad 0<\beta<1,
$$

where $u_{s}(k)=\frac{1}{1-\rho} C_{s}^{1-\rho}(k)+\chi \ln \left(\frac{M_{s}(k)}{P_{s}}\right)-\frac{\eta}{1+\psi} L_{s}^{1+\psi}(k), \rho>0$.

$C(k)$ is a consumption index, $M(k) / P$ are domestic real balances, and $L(k)$ is the labor supply of the representative home agent. Consumption is decomposed into the consumption of home and foreign composites, with elasticity of substitution $\theta$ between composites. In turn, the home (foreign) composite is defined over a continuum of $n(1-n)$ goods, with elasticity $\lambda$ between individual goods.

The consumer price index may be written as $P_{t}=\left(n P_{h t}^{1-\theta}+(1-n) P_{f t}^{1-\theta}\right)^{\frac{1}{1-\theta}}$, where $P_{i t}$ represents the price index of country $i$ 's goods for sale in the home country. Prices set in foreign currency are denoted with an asterisk. Prices for each period are set before all information about the period is known. All goods sold by local firms are priced in local currency, but when exporting, firms can follow PCP or LCP. Let the fraction of home (foreign) firms that engage in LCP be $z\left(z^{*}\right)$. For now we take these values as given.

Using this notation, the home country price index of foreign goods is

$$
P_{f t}=\left[\frac{1}{1-n} \int_{n}^{n+\left(1-z^{*}\right)(1-n)}\left(S_{t} P_{f h t}^{*}(i)\right)^{1-\lambda} d i+\frac{1}{1-n} \int_{n+\left(1-z^{*}\right)(1-n)}^{1} P_{f h t}(i)^{1-\lambda} d i\right]^{\frac{1}{1-\lambda}}
$$


where the notation $P_{f h t}(i)$ and $P_{f h t}^{*}(i)$ represents the domestic-currency and foreign-currency price of foreign goods sold in the home market. Holding goods prices fixed, the pass-through from exchange rate changes to home prices depends on the number of foreign firms following LCP. As $z^{*} \rightarrow 1$, passthrough is zero.

Home households' expenditure consists of consumption and the accumulation of money balances and bonds. Their revenues come from wage income, the earnings of profits from home country firms, payment on pre-existing bonds, money balances carried over, and transfers from the monetary authority. They choose consumption, their wage rate (given their individual monopoly power over their differentiated labor), bonds and money balances to maximize utility. We make the assumption that international financial markets are imperfect. Consumers can trade abroad only in non-contingent nominal bonds. Thus, there is incomplete international risk sharing. Within the domestic economy however, we assume that there is full risk sharing across households. This eliminates the specific uncertainty in wage income across types of households. Because utility is additively separable between consumption and labor, this implies that households will have equal consumption, whether or not they adjust wages ex-post.

Firms produce using labor only, with constant returns to scale. Since we wish to allow for some stickiness in wages, we follow Obstfeld and Rogoff (2000) in assuming that production uses differentiated labor, with elasticity of demand $\omega$ between types of labor. To maintain symmetry in the model, assume that any individual firm uses workers of each type. Therefore, the production function for firm $i$ in the home country is

$$
Y(i)=\left[\left(\frac{1}{n}\right)^{\frac{1}{\omega}} \int_{0}^{n} L(k, i)^{1-\frac{1}{\omega}} d k\right]^{\frac{1}{1-\frac{1}{\omega}}} .
$$

Given a distribution of wages $W(k)$, it is easy to show that the firm's marginal cost of production is given by $\left(\frac{1}{n} \int_{0}^{n} W(k)^{1-\omega} d k\right)^{\frac{1}{1-\omega}}$. Each worker then faces a specific labor demand curve with wage 
elasticity of demand $\omega$. The firm will choose its price to maximize the state-contingent value of profits. Since firms are owned by domestic households, they evaluate profits at the same state-contingent prices that are used for trading between domestic agents.

\section{Equilibrium Conditions}

Table 1 outlines the main equations of the model. Table 1a describes the optimality conditions for the consumer and the firm. The consumer chooses a stock of domestic currency denominated bonds to maximize utility, given the nominal interest rate $r_{t+1}$. Money demand depends positively on consumption and negatively on the nominal interest rate. Each consumer-worker sets the wage as a markup over the marginal rate of substitution between consumption and leisure. A fraction $v$ of the total $n$ workers set wages ex-post, after the state of the world is realized, while the fraction $1-v$ set wages in advance. The nominal discount factor used by firms in their evaluation of expected profits is now defined as $d_{t-1}=\beta \frac{C_{t-1}^{\rho} P_{t-1}}{C_{t}^{\rho} P_{t}}$. Wage and price indices are described in Table $1 \mathrm{~b}$.

Table 1c describes the market clearing relationships. Employment of fixed wage and flexiblewage workers will in general differ (although the income effects of this are diversified away). The home country current account (per capita) is equal to total income per capita less consumption. $B_{t+1}$ represents the home country's stock of net foreign assets (denominated in the home currency). All home consumers receive the same income, where income comes from sales to domestic consumers and sales to foreign consumers, through both PCP and LCP firms.

\section{Model Solution}

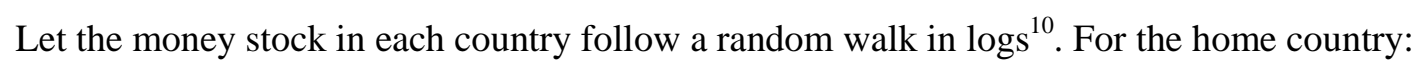

$$
\ln M_{t+1}=\ln M_{t}+u_{t+1} \quad E_{t}\left(u_{t+1}\right)=0
$$

\footnotetext{
${ }^{9} \mathrm{We}$ omit the presentation of the conditions over the choice of within-country state-contingent assets, because from the Mathematical Appendix we know this just leads to full consumption insurance across agents within a country.

${ }^{10}$ We take the monetary policy shocks as exogenous. But since we allow for arbitrary covariance between home and foreign money shocks, our framework in principle allows for any exchange rate outcome, ranging from free floats (when shocks are independent), to a pegged exchange rate (when shocks are collinear).
} 
We may solve by linear approximation around an initial non-stochastic equilibrium. The full linear approximation is derived in Appendix B. In order to determine the currency in which firms set their prices, the only information we need is the second moment properties of the log of the exchange rate and wages. But this is exactly what is obtained from the linear approximation. Let

$x_{t+j}=\ln X_{t+j}-E_{t-1} \ln X_{t+j}$ represent the log deviation from time $t-1$ expectation for any variable $X_{t+j}$, $j \geq 0$. A very convenient property of the money demand specification, in combination with the assumption about the money supply process, is that the nominal interest rate is constant. This is because, given that the $\log$ of the money stock follows a random walk, so does the $\log$ of the term $P_{t} C_{t}^{\rho}$. Using this fact, taking the money market equilibrium for the home country from Table 1a, and the analogous conditions for the foreign country, linearizing, and taking differences, gives

$$
c_{t}-c_{t}^{*}=\frac{m_{t}-m_{t}^{*}}{\rho}-\frac{\left(1-z n-z^{*}(1-n)\right) s_{t}}{\rho} .
$$

When there is full pass-through of exchange rates into prices, i.e. $z=z^{*}=0$, purchasing power parity holds at all times, and (2.1) represents a simple 'monetary model' of the exchange rate. Alternatively, with $z=z^{*}=1$, shocks to relative consumption are determined by shocks to relative money supplies alone.

From time $t+1$ onwards, in expectation, there is full money neutrality (in the linear approximate model). Then, using the time $t+1$ balance of payments condition, labor market and product market clearing (and using the notation $d B_{t+1}=B_{t+1}-B_{t}$ ), we may establish that

$$
E_{t}\left(c_{t+1}-c_{t+1}^{*}\right)=\frac{r}{\sigma} \frac{d B_{t+1}}{(1-n) \bar{P} \bar{C}}
$$

where $\sigma=\frac{(\psi \theta+(1-\rho)+\rho \theta)}{(\psi \theta+1)}, r$ represents the steady state interest rate (equal to $\left.\frac{1}{\beta}-1\right)$, and $\bar{P} \bar{C}$ describes the initial steady state value of nominal consumption. This condition says that, if the home 
country is expected to have an increase in net foreign assets, beginning in time $t+1$, then it is also expected to have an increase in its relative consumption $\stackrel{11}{ }$

Using the balance of payments condition for time $t$, the expressions for foreign and domestic sales, and the price indices from Table $1 \mathrm{~b}$, we obtain the following

$$
c_{t}-c_{t}^{*}+\frac{d B_{t+1}}{(1-n) \bar{P} \bar{C}}=\left[(\theta-1)\left(1-z(1-n)-z^{*} n\right)+(1-n) z^{*}+n z\right] s_{t} .
$$

This equation says that shocks to the exchange rate, by affecting the relative income of the home and foreign country, affect the path of relative consumption and the current account. Then, putting (2.2) and (2.3) together, we obtain

$$
c_{t}-c_{t}^{*}+\frac{\sigma}{r} E_{t}\left(c_{t+1}-c_{t+1}^{*}\right)=\left[(\theta-1)\left(1-z(1-n)-z^{*} n\right)+(1-n) z^{*}+n z\right] s_{t} .
$$

Equation (2.4) says that the income effects of exchange rate changes are spread over current and expected future relative consumption.

Finally, from the home and foreign Euler equations (Table 1a), we may obtain the following condition relating consumption growth across the two countries (using $E_{t} s_{t+1}=s_{t}$ ):

$$
E_{t}\left(c_{t+1}-c_{t+1}^{*}\right)=c_{t}-c_{t}^{*}-\frac{\left(z n+z^{*}(1-n)\right)}{\rho} s_{t} .
$$

Equation (2.5) says that an unanticipated exchange rate depreciation in period $t$, by causing a real exchange rate depreciation for the home country (when $z, z^{*} \neq 0$ ), reduces the relative home country interest rate, and causes a fall in expected consumption growth in the home country, relative to the foreign country.

We may put (2.1)-(2.5) together to obtain a solution for the impact of money shocks on the current exchange rate. This is given by:

$$
s_{t}=\frac{\left(1+\frac{\sigma}{r}\right)\left(m_{t}-m_{t}^{*}\right)}{\Delta}
$$

\footnotetext{
${ }^{11}$ Since our linear approximation is taken around an initial symmetric steady state with $B=0$, the net foreign
} 
where $\Delta=\left[\left(1+\frac{\sigma}{r}\right)+\left(z n+z^{*}(1-n)\right)(\rho-1)+\rho(\theta-1)\left(1-z(1-n)-z^{*} n\right)\right]$.

The response of the exchange rate to unanticipated money shocks depends on the elasticity of demand for home goods, the inter-temporal elasticity of substitution, and the measure of LCP firms in the home and foreign countries. Two special cases of (2.6), reported in Table 2 are of particular interest.

With full pass-through from exchange rates to price $\left(\mathrm{z}=\mathrm{z}^{*}=0\right)$, the response of the exchange rate is lower, the greater is the elasticity of demand between home and foreign goods. On the other hand, when passthrough is zero $\left(\mathrm{z}=\mathrm{z}^{*}=1\right)$, the exchange rate response is negatively related to $\rho$, the consumption elasticity of money demand.

From Table 1 we also derive the response of marginal cost to a money shock as:

$$
w_{t}=v\left(m_{t}+\psi l_{t}^{a}\right)
$$

The employment response to a money shock is:

$$
l_{t}^{a}=-\omega(1-v) w_{t}^{a}+n c_{t}+(1-n) c_{t}^{*}+(1-n) \theta\left(1-n z^{*}-z(1-n)\right) s_{t}
$$

Employment depends negatively upon the wage of the flexible wage setters, positively on the movement in aggregate world consumption, and, through 'expenditure switching' effects, positively on the nominal exchange rate, so long as there is some pass-through of exchange rates into prices (i.e. when $z, z^{*}<1$ ).

From the money market equilibrium conditions in Table 1a, the movement in world consumption is:

$$
n c_{t}+(1-n) c_{t}^{*}=\frac{n m_{t}+(1-n) m_{t}^{*}-(1-n) n\left(z-z^{*}\right) s_{t}}{\rho}
$$

An unanticipated increase in home or foreign money raises world consumption. But in addition, when $z \neq z^{*}$, an exchange rate depreciation has a compositional impact on total consumption. For instance, when $z>z^{*}$, a depreciation raises the home CPI more than it reduces the foreign CPI. Ceteris paribus, this implies that a weighted sum of home and foreign consumption will fall.

assets term enters in terms of rates of change, rather than proportional rates of change. 
We now put the components of section 1 and section 2 together, examining the interaction between the determination of exchange rates and exchange rate pass-through.

\section{Section 3. Equilibrium Pass-through with Identical Monetary Policies}

We evaluate the conditions underlying proposition 1 and its corollary, using the results from (2.6),

(2.7), and (2.8). First, define the function $\Phi\left(z, z^{*}, \sigma_{u}^{2}, \sigma_{u^{*}}^{2}\right)$ as the relative benefit to the firm of pricing by LCP as opposed to PCP. That is:

$$
\Phi\left(z, z^{*}, \sigma_{u}^{2}, \sigma_{u^{*}}^{2}\right)=\operatorname{cov}_{t-1}\left(w_{t}, s_{t}\right)-\frac{\operatorname{var}_{t-1}\left(s_{t}\right)}{2}
$$

Because exchange rate variance and the covariance of marginal cost and the exchange rate depend on the underlying monetary shocks, as well as on the measure of firms in each country following LCP, we may write the function in this way. In the same way, we define $\Phi^{*}\left(z, z^{*}, \sigma_{u}^{2}, \sigma_{u^{*}}^{2}\right)$ as:

$$
\Phi^{*}\left(z, z^{*}, \sigma_{u}^{2}, \sigma_{u^{*}}^{2}\right)=-\operatorname{cov}_{t-1}\left(w_{t}^{*}, s_{t}\right)-\frac{\operatorname{var}_{t-1}\left(s_{t}\right)}{2}
$$

Table 3 uses the results from section 2 to define the conditional variance of the exchange rate and the conditional covariance of exchange rate and marginal costs. We first focus on symmetric equilibria, where $n=0.5, \sigma_{u}^{2}=\sigma_{u^{*}}^{2}, \Phi=\Phi^{*}$, and $z=z^{*}$. Countries are therefore identical in all respects, and firms in the home and foreign country follow the same pricing policy.

There are three candidate symmetric equilibria, described as follows:

A) Symmetric PCP, $z=z^{*}=0$. This requires $\Phi\left(0,0, \sigma_{u}^{2}, \sigma_{u}^{2}\right)<0$,

B) Symmetric LCP, $z=z^{*}=1$. This requires $\Phi\left(1,1, \sigma_{u}^{2}, \sigma_{u}^{2}\right)>0$,

C) Symmetric mixed, $0 \leq z=z^{*} \leq 1$. This requires $\Phi\left(z, z, \sigma_{u}^{2}, \sigma_{u}^{2}\right)=0$. 
In the third case, at the equilibrium value of $z$, firms are indifferent between pricing in the home and foreign currency 12

To establish the existence of equilibrium we need to evaluate the $\Phi$ function at each value of $z$.

It is easy to establish that in the symmetric case:

$$
\Phi\left(z, z, \sigma_{u}^{2}, \sigma_{u}^{2}\right) \propto \tilde{v}\left[\left(\rho(\theta-1)+\psi \theta\left(1+\frac{\sigma}{r}\right)\right)(1-z)+(\rho-1) z\right]-\left(1+\frac{\sigma}{r}\right)(1-\tilde{v})
$$

where the term ' $\propto$ ' denotes 'proportional to', and $\tilde{v}=\frac{v}{1+\psi \omega(1-v)}<1$.

Using expression (3.1), we may establish the following proposition

\section{Proposition 2: Symmetric equilibrium}

a) If $\theta>\frac{1+\left(1+\frac{\sigma}{r}\right) \frac{(1-\tilde{v})}{\rho \tilde{v}}}{1+\frac{\psi}{\rho}\left(1+\frac{\sigma}{r}\right)}$, and $\rho>1+\left(1+\frac{\sigma}{r}\right) \frac{(1-\tilde{v})}{\tilde{v}}$, LCP is the unique equilibrium.

b) If $\theta<\frac{1+\left(1+\frac{\sigma}{r}\right) \frac{(1-\tilde{v})}{\rho \tilde{v}}}{1+\frac{\psi}{\rho}\left(1+\frac{\sigma}{r}\right)}$, and $\rho<1+\left(1+\frac{\sigma}{r}\right) \frac{(1-\tilde{v})}{\tilde{v}}$, PCP is the unique equilibrium.

c) If $\theta>\frac{1+\left(1+\frac{\sigma}{r}\right) \frac{(1-\tilde{v})}{\rho \tilde{v}}}{1+\frac{\psi}{\rho}\left(1+\frac{\sigma}{r}\right)}$ and $\rho<1+\left(1+\frac{\sigma}{r}\right) \frac{(1-\tilde{v})}{\tilde{v}}$ the unique equilibrium is $\bar{z} \in(0,1)$, such that

$\Phi\left(\bar{z}, \bar{z}, \sigma_{u}^{2}, \sigma_{u}^{2}\right)=0$

d) If $\theta<\frac{1+\left(1+\frac{\sigma}{r}\right) \frac{(1-\tilde{v})}{\rho \tilde{v}}}{1+\frac{\psi}{\rho}\left(1+\frac{\sigma}{r}\right)}$ and $\rho>1+\left(1+\frac{\sigma}{r}\right) \frac{(1-\tilde{v})}{\tilde{v}}$, there are three equilibria: PCP,

\footnotetext{
${ }^{12}$ How would firms coordinate on a mixed equilibrium, when they are indifferent between the two policies? One possibility is that they play a mixed strategy, choosing to follow LCP (PCP) with probability z (1-z), before choosing prices (Bachetta and Van Wincoop 2001, give this interpretation). An alternative possibility is that there are small differential firm-specific costs (e.g. menu costs) of choosing LCP as opposed to PCP. If we rank firms in
} 
LCP, and an interior (unstable) equilibrium $\hat{z} \in(0,1)$ such that $\Phi\left(\hat{z}, \hat{z}, \sigma_{u}^{2}, \sigma_{u}^{2}\right)=0$.

Proof: The proposition follows directly from applying the parameter restrictions to the conditions for the different types of candidate equilibria given above.

If the two inequalities given in part a hold, each firm has an incentive to set export prices in terms of the local currency, whatever other firms do. Thus, the only equilibrium can be one where all firms follow LCP. For LCP to be a unique symmetric equilibrium, the consumption elasticity of money demand must be at least unity, and the elasticity of substitution between home and foreign goods must be sufficiently high. The results are sensitive to the flexibility in marginal cost. If most wages are pre-set, then LCP cannot be an equilibrium. But if $v=1$, so that all wages are adjusted ex-post, then LCP is the unique equilibrium when $\rho>1$ and $\theta>1$.

If the two inequalities of part b hold, then each firm will follow PCP, no matter what other firms do. This outcome is more likely, the lower is $v$, and the lower are $\theta$ and $\rho$. In the first case, the calculation the firm makes is dominated by the variance of the exchange rate, since the covariance of marginal costs and the exchange rate is small when most wages are pre-set. In the second case, the lower are $\theta$ and $\rho$, the higher is the volatility of the exchange rate, relative to the $\operatorname{cov}_{t-1}\left(w_{t}, s_{t}\right)$ term, whatever pricing policy is chosen. As a result the optimal policy for all firms is to choose PCP.

In part c, the incentives for pricing will depend on what other firms do. If all firms follow PCP, then any one firm would have an incentive to deviate and choose LCP. But if all firms follow LCP, then again, any one firm would have an incentive to deviate and choose PCP. Thus, there is no equilibrium where all firms follow the same pricing policy. By continuity, an intermediate equilibrium exists in which some firms follow PCP and some firms LCP. For a given value of $v$, this outcome is more likely, the higher is $\theta$ and the lower is $\rho$. In that case, exchange rate volatility is quite low under PCP, relative to $\operatorname{cov}_{t-1}\left(w_{t}, s_{t}\right)$, giving firms an incentive to engage in LCP. But if all firms follow LCP, then with a

order of increasing costs, then the mixed equilibrium would be a limit outcome as the scale of these differential costs approaches zero. 
low value of $\rho$, exchange rate volatility is high, relative to $\operatorname{cov}_{t-1}\left(w_{t}, s_{t}\right)$. This means that LCP is not an equilibrium. In the intermediate equilibrium $(1-\bar{z})$ firms follow PCP and $\bar{z}$ firms follow LCP. No firm has an incentive to deviate from this outcome. The key feature giving rise to a unique equilibrium is the presence of a negative relationship between pass-through and exchange rate volatility.

Part $\mathrm{d}$ is the opposite of part c. In this case, all firms have an incentive to follow PCP if all other firms do also. Conversely, all firms have an incentive to follow LCP if all other firms do also. For a given value of $v$, this outcome is more likely, the lower is $\theta$ and the higher is $\rho$. Exchange rate volatility is then quite high under PCP, relative to $\operatorname{cov}_{t-1}\left(w_{t}, s_{t}\right)$, giving firms and incentive to engage in PCP, when all other firms do so. But if all firms follow LCP, then with a high value of $\rho$, exchange rate volatility is low. This encourages firms to engage in LCP when other firms also follow LCP. Thus, both $z=0$ and $z=1$ are equilibria. ${ }^{13}$ A positive relationship between exchange rate pass-through and exchange rate volatility thus gives rise to the possibility of non-uniqueness.

Can there be pure strategy asymmetric equilibria in the symmetric model? No. In the symmetric model, $\operatorname{cov}(w, s)$ and $-\operatorname{cov}\left(w^{*}, s\right)$ differ only in the $z-z^{*}$ term that appears in each expression in Table 3. If $z>z^{*}$, then $\operatorname{cov}(w, s)<-\operatorname{cov}\left(w^{*}, s\right)$ implying that $\Phi<\Phi^{*}$. The latter inequality cannot be consistent with home firms choosing LCP $(\Phi>0)$ and foreign firms choosing PCP $\left(\Phi^{*}<0\right)$. Hence, assuming $z>z *$ leads to a contradiction.

Figure 1 describes the four possible equilibrium configurations, in terms of the value of the $\Phi\left(z, z, \sigma_{u}^{2}, \sigma_{u}^{2}\right)$ function over the range of $z$. Figure 1a describes the unique LCP outcome. Figure $1 \mathrm{~b}$ shows the unique PCP outcome. In each case the equilibrium is unique because the gain to following LCP is positive (negative) irrespective of the choice of other firms. Figure 1c shows the unique intermediate outcome, while Figure 1d illustrates the possibility of multiple equilibria.

\footnotetext{
${ }^{13}$ There is also an internal equilibrium. This equilibrium is unstable, however, since if a small measure of firms deviate by increasing (decreasing) $z$, then all others will wish to follow, so that $z$ goes to $1(0)$.
} 
We note from the figures that multiple equilibria are possible only when the $\Phi\left(z, z, \sigma_{u}^{2}, \sigma_{u}^{2}\right)$

function is upward sloping. The slope of the function is (positively) proportional to

$$
-\tilde{v}\left[\rho(\theta-1)+\psi \theta\left(1+\frac{\sigma}{r}\right)+1-\rho\right]
$$

As suggested by the proposition, this is more likely to be positive, the higher is $\rho$, and the lower is $\theta$. More informally, multiple equilibria are more likely when LCP tends to be associated with low exchange rate volatility, and PCP tends to be associated with high exchange rate volatility. Empirically, however, multiple equilibria are not very likely in our model. The empirically relevant range of $\theta$ exceeds unity, and should certainly exceed the consumption elasticity of money demand $\rho$.

Note that Proposition 2 does not depend on distribution of the money supplies. With identical monetary variances, both the variance of the exchange rate and the covariance of exchange rates and marginal costs are affected equally by monetary variability.

In case c), the equilibrium $\bar{z}$ is given by

$$
\bar{z}=\frac{\rho(\theta-1)+\left(1+\frac{\sigma}{r}\right)\left(\psi \theta-\frac{(1-\tilde{v})}{\tilde{v}}\right)}{\rho(\theta-1)+\psi \theta\left(1+\frac{\sigma}{r}\right)+1-\rho} .
$$

Inspection of (3.3) indicates that $\bar{z}$ is increasing in $\tilde{v}$. As a greater fraction of wages are set ex-post, the equilibrium degree of pass-through declines. Similarly, $\bar{z}$ is increasing in $\rho$ and $\theta$. Both parameters tend to reduce exchange rate volatility for any given $z$, increasing the number of firms who engage in LCP.

This case illustrates an important implication of Proposition 2; the relationship between exchange rate volatility and economic structure may be substantially altered by the endogeneity of exchange rate pass-through. To illustrate, take a special case where $\psi=0$ and $\tilde{v}=1$. With pass-through taken as given, we may re-write the expression for exchange rate volatility as 


$$
\frac{\left(1+\frac{\sigma}{r}\right)^{2}\left(\sigma_{u}^{2}+\sigma_{u^{*}}^{2}-2 \sigma_{u u^{*}}\right)}{\left[1+\frac{\sigma}{r}+(\rho-1) z+\rho(\theta-1)(1-z)\right]^{2}} .
$$

If we begin in a situation where $\theta>1, \rho>1$, so that $z=1$ holds (part a of the proposition), then all firms

follow LCP. In this case, the exchange rate volatility is $\left(\frac{1+\frac{\sigma}{r}}{\frac{\sigma}{r}+\rho}\right)^{2}\left(\sigma_{u}^{2}+\sigma_{u^{*}}^{2}-2 \sigma_{u u^{*}}\right)$. Here, exchange rate volatility is less than the variance of monetary fundamentals, $\left(\sigma_{u}^{2}+\sigma_{u^{*}}^{2}-2 \sigma_{u u^{*}}\right)$. Now let $\rho$ fall below unity. Ignoring the response of pass-through, we would predict that this would increase exchange rate volatility, so that volatility exceeded the variance of monetary fundamentals. But in our model, this will not happen. When $\rho$ falls below unity, part $\mathrm{c}$ of the proposition (or Figure 1c) applies. Now we have pass-through falling, so that $\bar{z}=\frac{\rho(\theta-1)}{\rho(\theta-1)+1-\rho}$. Exchange rate volatility is now given by $\left(\sigma_{u}^{2}+\sigma_{u^{*}}^{2}-2 \sigma_{u u^{*}}\right)$. In this example, when endogenous pass-through is taken into account, exchange rate volatility will never exceed the monetary fundamentals.

\section{Section 4. Pass-through with Differential Monetary Policies}

We now allow for differences in money growth volatility across countries. To focus on the effects of different volatilities, we assume in this section that the money shocks are uncorrelated across countries. Without loss of generality, assume that the home country has lower monetary growth volatility than the foreign country. As discussed in footnote 9 , we may think of equilibria where firms employ mixed strategies. Thus, if $\Phi\left(z, z^{*}, \sigma_{u}^{2}, \sigma_{u^{*}}^{2}\right)=0$ and $\Phi^{*}\left(z, z^{*}, \sigma_{u}^{2}, \sigma_{u^{*}}^{2}\right)=0$ we say $\left\{z, z^{*}\right\}$ is an equilibrium where each home (foreign) firm chooses a probability $z\left(z^{*}\right)$, ex ante, of setting its export price in foreign (home) currency, and $1-z,\left(1-z^{*}\right)$ of setting its price in home (foreign) currency.

To simplify the presentation of results, we first make the additional assumption that preferences display linearity in labor supply, so that $\psi=0$. This assumption is commonly used in the literature on 
exchange rates and price stickiness (Devereux and Engel 2001, Corsetti and Pesenti 2001). Qualitatively, none of the results are affected by the assumption. The general case where $\psi>0$ is used in the simulations below. In addition, further to our discussion of the last section, we focus only on the cases of unique equilibrium. Thus, we restrict attention to the set of equilibria where the $\Phi$ and $\Phi^{*}$ functions are downward sloping. 14

Using Table 3, it may be established that

$$
\begin{aligned}
& \Phi \propto \tilde{v}\left[1+\frac{\sigma}{r}+\left(z n+z^{*}(1-n)\right)(\rho-1)+\rho(\theta-1)\left(1-z(1-n)-z^{*} n\right)\right]-\left(1+\frac{\sigma}{r}\right) \frac{\left(\sigma_{u}^{2}+\sigma_{u^{*}}^{2}\right)}{2 \sigma_{u}^{2}} \\
& \Phi^{*} \propto \tilde{v}\left[1+\frac{\sigma}{r}+\left(z n+z^{*}(1-n)\right)(\rho-1)+\rho(\theta-1)\left(1-z(1-n)-z^{*} n\right)\right]-\left(1+\frac{\sigma}{r}\right) \frac{\left(\sigma_{u}^{2}+\sigma_{u^{*}}^{2}\right)}{2 \sigma_{u^{*}}^{2}}
\end{aligned}
$$

From these two expressions, we may establish the following proposition.

\section{Proposition 3}

Let $\Omega=\left(1+\frac{\sigma}{r}\right) \frac{\left(\sigma_{u}^{2}+\sigma_{u^{*}}^{2}\right)}{2 \sigma_{u}^{2}}, \quad \Omega^{*}=\left(1+\frac{\sigma}{r}\right) \frac{\left(\sigma_{u}^{2}+\sigma_{u^{*}}^{2}\right)}{2 \sigma_{u^{*}}^{2}}$, and

$\Gamma\left(z, z^{*}\right)=\tilde{v}\left[1+\frac{\sigma}{r}+\left(z n+z^{*}(1-n)\right)(\rho-1)+\rho(\theta-1)\left(1-z(1-n)-z^{*} n\right)\right]$. Note that from our

assumption that $\sigma_{u^{*}}^{2}>\sigma_{u}^{2}$, we have $\Omega>\Omega^{*}$. The equilibrium is described by the set $\mu=\left\{z, z^{*}\right\}$. The equilibrium has the following properties:

a) If $\Gamma(1,1)=\tilde{v}\left(\frac{\sigma}{r}+\rho\right)>\Omega$, then $\mu=\{1,1\}$

b) If $\Gamma(\hat{z}, 1)=\tilde{v}\left(1+\frac{\sigma}{r}+(1-n+\hat{z} n)(\rho-1)+\rho(\theta-1)(1-n)(1-\hat{z})\right)=\Omega$ and $0<\hat{z}<1$, then $\mu=\{\hat{z}, 1\}$.

c) If $\Omega^{*}<\Gamma(0,1)=\tilde{v}\left(1+\frac{\sigma}{r}+(1-n)(\rho-1)+\rho(\theta-1)(1-n)\right)<\Omega$, then $\mu=\{0,1\}$.

\footnotetext{
${ }^{14}$ In the specific case where $\psi=0$, this requires that $\rho(\theta-1)(1-n)-(\rho-1) n>0$ and
} 
d) If $\Omega^{*}=\Gamma\left(0, \hat{z}^{*}\right)=\tilde{v}\left(1+\frac{\sigma}{r}+\hat{z}^{*}(1-n)(\rho-1)+\rho(\theta-1)\left(1-n \hat{z}^{*}\right)\right)$ and $0<\hat{z}^{*}<1$, then $\mu=\left\{0, \hat{z}^{*}\right\}$

e) If $\Gamma(0,0)=\tilde{v}\left(1+\frac{\sigma}{r}+\rho(\theta-1)\right)<\Omega^{*}$, then $\mu=\{0,0\}$.

Proof: For each part, the proof follows by direct construction. In case a), if $\Gamma(1,1)$ exceeds $\Omega$, then full LCP is an equilibrium for both the home and foreign firms. Moreover, because we assume that $\Gamma\left(z, z^{*}\right)$ is decreasing in both variables (i.e. because we rule out multiple equilibria), this is the only equilibrium outcome. In case b), a measure $\hat{z}$ of home country firms follow LCP, while all foreign firms follow LCP. Note that $\hat{z}$ is implicitly defined by the equality $\Gamma(\hat{z}, 1)=\Omega$. In case $\mathrm{c})$, all home country firms follow PCP, whereas foreign firms all follow LCP. In case d), all home country firms follow PCP, while a measure $\hat{z}^{*}$ of foreign firms follow LCP. Finally, in case e), all firms, both home and foreign, follow PCP.

Proposition 3 implies that the exchange rate pass-through into the home economy is always less than or equal to that into the foreign economy. A fall in the volatility of home money growth will either leave exchange rate pass-through into the home economy unchanged, or decrease it. Conversely, exchange rate pass-through into the foreign country either remains unchanged, or increases. Thus, firms tend to set their export prices in the currency that is associated with the more stable monetary growth.

Which of the five categories of Proposition 3 will come about depends on parameter values, and the relative size of money growth variances? As in section 3, the smaller is $v$, the fraction of wage contracts that are subject to ex-post adjustment, the more likely that firms in both countries will follow PCP, since marginal costs will tend to have a smaller covariance with exchange rate movements. For a given $\rho$, the greater is the elasticity of substitution between home and foreign products, $\theta$, the more likely is LCP, since exchange rate variance will, ceteris paribus, be smaller. When the variance of money $\rho(\theta-1) n-(\rho-1)(1-n)>0$. 
growth, relative to foreign money growth, falls to zero, exchange rate pass-through into the foreign country becomes complete. The reason is that reducing home money growth variance to zero tends to fully stabilize marginal cost for the home country. With a positive exchange rate variance determined by foreign monetary instability, it is therefore always optimal for home country firms to set prices in their domestic currency. For foreign firms on the other hand, the variance of the exchange rate tends to fall, relative to the covariance of the exchange rate and marginal cost, since more and more of exchange rate volatility is driven by their own monetary shocks; the same shocks that are driving marginal costs.

Now take a particular example of the impact of changes in the variance of monetary growth and focus on it more closely.

\section{Proposition 4.}

Begin in an initial symmetric equilibrium $\mu=\{\tilde{z}, \tilde{z}\}$, where $\Gamma(\tilde{z}, \tilde{z})=(1+\sigma / r)$, with $0<\tilde{z}<1$. Then a fall in the variance of home country monetary growth will reduce pass-through into the home country, and increase pass-through into the foreign country. The new equilibrium will be either a) $\mu=\left\{z^{\prime}, 1\right\}$, b) $\mu=\{0,1\}$, or c) $\mu=\left\{0, z^{*}\right\}$, where $z^{\prime}<\tilde{z}$, and $z^{*^{\prime}}>\tilde{z}$.

Proof: Using the same arguments as Proposition 3, it is easy to show that the impact of the fall in the variance of home country monetary growth must lead to one of cases b), c) or d) of Proposition 3 . In particular, given that the function $\Gamma\left(z, z^{*}\right)$ is common to both countries, the impact of a fall in monetary growth in the home country is either to fully eliminate exchange rate pass-through into the domestic economy, or to increase pass-through to 100 percent in the foreign economy. With differences in monetary growth variance, it is no longer possible to have partial pass-through in both economies.

These results provide a theoretical rationale for the conjecture that low and stable inflation rates may lead to a reduction in the pass-through from exchange rate movements into the CPI. In our model, a fall in one country's monetary instability will reduce exchange rate pass-through into that country, and hence stabilize its price level from the effects of exchange rate movements. But the rate of pass-through depends on relative variances of monetary growth rates, not on the absolute variances. Thus, pass- 
through is unaffected by a parallel reduction in monetary growth instability in both countries. Moreover, a decline in pass-through in one economy as a result of stable monetary policy is synonymous with a rise in pass-through in its partner economies.

The model suggests an intriguing link between inflation targeting and price stability. In an inflation targeting country, price stability might be pursued by following a policy of low and stable domestic-goods inflation. If the country's inflation targeting policy leads to a stabilization of its money growth rate, it encourages foreign exporters to set prices in terms of its currency. In doing so, it stabilizes the imported goods component of its CPI, thereby enhancing price stability. But the flip side of this is that the policy also encourages domestic exporters to favor the home currency for price-setting of goods to be sold in foreign markets. As a result the foreign price level becomes more unstable. In this respect, there is a type of 'beggar-thy-neighbor' feature in the determination of exchange rate pass-through, and more generally in the effect of monetary policy on price stability in an open economy with endogenous pass-through.

Figure 2 and 3 illustrate the results with the more general model, without the assumption of linearity in labor supply in the utility function. Since the $\Phi$ and $\Phi *$ functions are no longer linearly dependent (in $z$ and $z^{*}$ ), it is now possible that there are simultaneous interior equilibrium values for passthrough in both countries. The parameter values used are reported in Table 4, and are mostly quite standard.

Figure 2, shows the impact of a decline in the volatility of monetary growth in the home country, starting from the point of equal money growth volatility. Normalizing so that the initial variances are unity, the horizontal axis measures $\left(1-\sigma_{u}^{2}\right)$, or the percentage fall in home country monetary variance. In this example, we assume that 75 percent of wage contracts are adjusted ex post. At the initial point, $z=z^{*}=0.47$, so there is pass-through equal to 53 percent. As $\sigma_{u}^{2}$ falls however, $z$ falls sharply, and $z^{*}$ increases, so that pass-through into the foreign economy increases to 100 percent when $\sigma_{u}^{2}$ falls 30 
percent below $\sigma_{u^{*}}^{2}$, and pass-through into the home economy falls to zero when $\sigma_{u}^{2}$ falls 50 percent below $\sigma_{u^{*}}^{2}$.

Figure 3 illustrates the case where only 50 percent of wage contracts are adjusted ex post $(v=0.5)$.

In this case, the initial symmetric equilibrium is one where both firms follow PCP. But as $\left(1-\sigma_{u}^{2}\right)$ rises to .55 , foreign firms switch quite quickly to LCP, and $z$ rises to unity. Pass-through into the home economy falls to zero. This example points quite dramatically to the importance of relative volatility of money growth in determining exchange rate pass-through in our environment. The initial symmetric equilibrium in this example indicates a very strong preference for PCP, given that marginal cost shows little ex-post responsiveness to the exchange rate. But the change in relative monetary variability increases the importance of marginal costs for foreign firms so much that they will switch over to pricing in home currency.

\section{Conclusions}

This paper develops a general framework for analyzing the determinants of exchange rate passthrough in an open economy macroeconomic model. We find that the relationship between structural parameters and exchange rate volatility can be altered dramatically when pass-through is endogenized. This is an example of the Lucas critique - changes in economic policy may lead to changes in equilibrium decision rules. We have given one example where changes in relative monetary stability have very strong implications for equilibrium exchange rate pass-through in both countries. Our findings suggest that monetary policy analysis that takes the amount of pass-through as given misses one of the key channels through which monetary policy may work - by changing the degree of pass-through.

More generally, we conjecture that allowing for endogenous exchange rate pass-through may have significant implications for the international transmission of shocks, for optimal monetary policy, and for the gains from international coordination of monetary policies. 


\section{References}

Bacchetta, Philippe, and Eric van Wincoop, 2000, "Does Exchange Rate Stability Increase Trade and Welfare?" American Economic Review 90, 1093-1109.

Bacchetta, Philippe, and Eric van Wincoop, 2001, "Trade Flows, Prices and the Exchange Rate Regime," in Revisiting the Case for Flexible Exchange Rates (Bank of Canada), 213-231.

Bacchetta, Philippe, and Eric van Wincoop, 2002, "A Theory of the Currency Denomination of International Trade," Study Center Gerzensee, mimeo.

Blanchard, Olivier, and Nobuhiro Kiyotaki, 1987, "Monopolistic Competition and the Effects of Aggregate Demand," American Economic Review 77, 647-666.

Betts, Caroline and Michael B. Devereux, 1996, "The Exchange Rate in a Model of Pricing to Market," European Economic Review, 40, 1007-1021.

Betts, Caroline and Michael B. Devereux, 2000, "Exchange Rate Dynamics in a Model of Pricing to Market," Journal of International Economics 50, 215-244.

Corsetti, Giancarlo and Paolo Pesenti, 2001, "Optimal Interest Rate Rules and Exchange Rate PassThrough,” Federal Reserve Bank of New York, mimeo.

Devereux, Michael B., and Charles Engel, 2000, "Monetary Policy in the Open Economy Revisited: Price Setting and Exchange Rate Flexibility," National Bureau of Economic Research, working paper no. 7665 .

Devereux, Michael B. and Charles Engel, 2001, "Endogenous Currency of Pricing in a Dynamic Open Economic Model," National Bureau of Economic Research working paper no. 8559.

Engel, Charles, 1993, "Real Exchange Rates and Relative Prices: An Empirical Investigation," Journal of Monetary Economics 32, 35-50.

Engel, Charles, and John H. Rogers, 1996, "How Wide is the Border?" American Economic Review 86, 1112-1125.

Feenstra, Robert C., 1989, "Symmetric Pass-Through of Tariffs and Exchange Rates under Imperfect Competition: An Empirical Test," Journal of International Economics 27, 25-45.

Feenstra, Robert C.; Joseph E. Gagnon; and, Michael M. Knetter, 1996, "Market Share and Exchange Rate Pass-Through in World Automobile Trade," Journal of International Economics 40, 187207.

Friberg, Richard, 1998, “In Which Currency Should Exporters Set Their Prices?” Journal of International Economics 45, 59-76.

Giovannini, Alberto, 1988, "Exchange Rates and Traded Goods Prices," Journal of International Economics 24, 45-68.

Goldberg, Pinelopi K., 1995, "Product Differentiaton and Oligopoly in International Markets: The Case of the U.S. Automobile Industry," Econometrica 63, 891-951. 
Goldberg, Pinelopi K., and Michael M. Knetter, 1997, "Goods Prices and Exchange Rates: What Have We Learned?" Journal of Economic Literature 35, 1243-1272.

Goldberg, Pinelopi K., and Frank Verboven, 2001, "The Evolution of Price Dispersion in the European Car Market," Review of Economic Studies 68, 811-48.

Knetter, Michael M., 1989, "Price Discrimination by U.S. and German Exporters," American Economic Review 79, 198-210.

Knetter, Michael M., 1993, "International Comparisons of Price-to-Market Behavior," American Economic Review 83, 473-486.

Krugman, Paul, 1987, "Pricing to Market when the Exchange Rate Changes," in S.W. Arndt and J.D. Richardson, eds., Real-Finanical Linkages Among Open Economies, Cambrdige: MIT Press.

Lane, Philip R., 2001, “The New Open Economy Macroeconomics: A Survey,” Journal of International Economics. 54, 235-266.

Obstfeld, Maurice, and Kenneth Rogoff, 1995, "Exchange Rate Dynamics Redux," Journal of Political Economy 103, 624-60.

Obstfeld, Maurice, and Kenneth Rogoff, 1998, "Risk and Exchange Rates," National Bureau of Economic Research, working paper no. 6694.

Obstfeld, Maurice, and Kenneth Rogoff, 2000, "New Directions for Stochastic Open Economy Models," Journal of International Economics 50, 117-153.

Parsley, David C., and Shang-Jin Wei, 2001, "Explaining the Border Effect: The Role of Exchange Rate Variability, Shipping Costs, and Geography," Journal of International Economics 55, 87-105.

Storgaard, Peter E., 2001, "Optimal Contract Currencies and Exchange Rate Policy" Chapter 4 of PhD Thesis, University of Aarhus, and Danmarks Nationalbank, working paper 3/2002.

Tille, Cédric, 2000, “'Beggar-Thy-Neighbor' or 'Beggar Thyself'? The Income Effects of Exchange-Rate Fluctuations," Federal Reserve Bank of New York, Staff Report 112. 


\section{Appendix A}

\section{Proof of proposition 1}

From (1.4), profits under PCP are given as

$$
E \Pi^{P C P}=\tilde{\lambda} E\left(S^{\lambda} Z\right)^{\lambda} E\left(S^{\lambda} Z W\right)^{1-\lambda} .
$$

This expression may be rewritten as

$$
\tilde{\lambda}(E \exp (\ln Z) \exp (\lambda \ln S))^{\lambda}(E \exp (\ln Z) \exp (\lambda \ln S) \exp (\ln W))^{1-\lambda} .
$$

Now use the second order approximation:

$$
\begin{aligned}
& E \exp (\ln Z) \exp (\lambda \ln S) \approx \exp (E \ln Z) \exp (\lambda E \ln S) \times \\
& \left(1+\frac{1}{2} \operatorname{var}(\ln Z)+\frac{\lambda^{2}}{2} \operatorname{var}(\ln S)+\lambda \operatorname{cov}(\ln Z, \ln S)\right)
\end{aligned}
$$

Using the same approximation for the expression $E \exp (\ln Z) \exp (\lambda \ln S) \exp (\ln W)$, we get an approximation for profits equal to

$$
\begin{aligned}
& \Sigma\left(1+\frac{1}{2} \operatorname{var}(\ln Z)+\frac{\lambda^{2}}{2} \operatorname{var}(\ln S)+\lambda \operatorname{cov}(\ln Z, \ln S)\right)^{\lambda} \\
& \times\left(\begin{array}{l}
1+\frac{1}{2} \operatorname{var}(\ln Z)+\frac{\lambda^{2}}{2} \operatorname{var}(\ln S)+\frac{1}{2} \operatorname{var}(\ln W) \\
+\lambda \operatorname{cov}(\ln S, \ln Z)+\operatorname{cov}(\ln Z, \ln W)+\lambda \operatorname{cov}(\ln S, \ln W)
\end{array}\right)^{1-\lambda},
\end{aligned}
$$

where $\Sigma=\tilde{\lambda} \exp (E \ln Z) \exp (\lambda E \ln S) \exp ((1-\lambda) E \ln W)$

Taking logs, we get expected discounted profits equal to

$$
\begin{aligned}
& \ln \Sigma+\left(\frac{1}{2} \operatorname{var}(\ln Z)+\frac{\lambda^{2}}{2} \operatorname{var}(\ln S)+\frac{(1-\lambda)}{2} \operatorname{var}(\ln W)\right)+ \\
& (\lambda \operatorname{cov}(\ln Z, \ln S)+\lambda(1-\lambda) \operatorname{cov}(\ln W, \ln S)+(1-\lambda) \operatorname{cov}(\ln Z, \ln W))
\end{aligned} .
$$

Now, expected discounted profits under LCP are written as

$$
E \Pi^{L C P}=\tilde{\lambda}[E Z S]^{\lambda}[E Z W]^{1-\lambda}
$$

Using the same approximation, they may be written as

$$
\begin{aligned}
& \ln \Sigma+\left(\frac{1}{2} \operatorname{var}(\ln Z)+\frac{\lambda}{2} \operatorname{var}(\ln S)+\frac{(1-\lambda)}{2} \operatorname{var}(\ln W)\right)+ \\
& (\lambda \operatorname{cov}(\ln Z, \ln S)+(1-\lambda) \operatorname{cov}(\ln Z, \ln W))
\end{aligned}
$$

Now comparing (A3), and (A4), we can immediately establish Proposition 1. 


\section{Appendix B}

Here we derive the results that are obtained in section 2 of the paper. The full model is described by the equations of Table 1 . This gives 16 equations for the home country, plus the balance of payments equation. Adding on 16 corresponding equations for the foreign country (the foreign country's balance of payments equation is dropped, by Walras' Law), we arrive at 33 equations in the 33 endogenous variables listed as follows: $C_{h t}, C_{f t}^{*}, C_{t}, C_{t}^{*}, W_{t}, W_{t}^{*}, W_{t}^{a}, W_{t}^{* a}, W_{t}^{f}, W_{t}^{* f} L_{t}^{a}, L_{t}^{* a}, L_{t}^{f}, L_{t}^{* f}, Y_{h t}, Y_{h f t}, Y_{h f t}^{*}, Y_{f t}$, $Y_{f h t}, Y_{f h t}^{*}, S_{t}, B_{t}, r_{t} P_{t}, P_{t}^{*}, P_{h t}, P_{f t}^{*}, P_{h t}^{*}, P_{f t}, P_{h f t}, P_{h f t}^{*}, P_{f h t}^{*}, P_{f h t}$.

\section{Solution technique}

To solve this system, we take a linear approximation around an initial symmetric steady state, where net foreign assets are zero, all prices are equal, and the exchange rate is initially unity. The solution procedure is as follows. First, we take the linear approximation around an initial steady state equilibrium. We define $\hat{x}_{t}=\ln X_{t}-\ln \bar{X}$, as a log deviation from the initial steady state. Define $x_{t+j}=\hat{x}_{t+j}-E_{t-1} \hat{x}_{t+j}$ as the unexpected component of the deviation from the initial steady state. Using this, we may compute the conditional variance and covariance of the exchange rate and marginal costs.

Then the linearized versions of the pricing equations of Table 1 are

$$
\begin{array}{ll}
\hat{p}_{t}=n \hat{p}_{h t}+(1-n) \hat{p}_{f t}=n \hat{p}_{h t}+(1-n)\left(\left(1-z^{*}\right)\left(\hat{s}_{t}+\hat{p}_{f h t}^{*}\right)+z^{*} \hat{p}_{f h t}\right) \\
\hat{p}_{t}^{*}=n \hat{p}_{h t}^{*}+(1-n) \hat{p}_{f t}^{*}=n\left(z \hat{p}_{h f t}^{*}+(1-z)\left(\hat{p}_{h f t}-\hat{s}_{t}\right)\right)+(1-n) \hat{p}_{f t}^{*} \\
\hat{p}_{h t}=E_{t-1} \hat{w}_{t} & \hat{p}_{f t}^{*}=E_{t-1} \hat{w}_{t}^{*} \\
\hat{p}_{h f t}^{*}=E_{t-1}\left(\hat{w}_{t}-\hat{s}_{t}\right) \quad \hat{p}_{h f t}=E_{t-1} \hat{w}_{t} \\
\hat{p}_{f h t}=E_{t-1}\left(\hat{w}_{t}^{*}+\hat{s}_{t}\right) \quad \hat{p}_{f h t}^{*}=E_{t-1}\left(\hat{w}_{t}^{*}\right)
\end{array}
$$

This implies that the CPI prices may be written as:

$$
\begin{aligned}
& \hat{p}_{t}=n E_{t-1} \hat{w}_{t}+(1-n)\left(\left(1-z^{*}\right)\left(\hat{s}_{t}+E_{t-1} \hat{w}_{t}^{*}\right)+z^{*} E_{t-1}\left(\hat{w}_{t}^{*}+\hat{s}_{t}\right)\right) \\
& \hat{p}_{t}^{*}=n\left((1-z)\left(E_{t-1} \hat{w}_{t}-\hat{s}_{t}\right)+z E_{t-1}\left(\hat{w}_{t}-\hat{s}_{t}\right)\right)+(1-n) E_{t-1} \hat{w}_{t}^{*} .
\end{aligned}
$$

Linearizing the balance of payments condition including the home and foreign demand schedules from Table 1 (where $d \hat{B}_{t} \equiv B_{t}-\bar{B}=B_{t}$ ) gives

$$
\begin{aligned}
& \hat{c}_{t}+\frac{d \hat{B}_{t+1}}{\bar{P} \bar{C}}=(1+r) \frac{d \hat{B}_{t}}{\bar{P} \bar{C}}+n \hat{c}_{t}+n(1-\theta)\left(\hat{p}_{h t}-\hat{p}_{t}\right) \\
& +(1-n) z\left[(1-\lambda)\left(\hat{p}_{h f t}^{*}-\hat{p}_{h t}^{*}\right)+(1-\theta)\left(\hat{p}_{h t}^{*}-\hat{p}_{t}^{*}\right)+\left(\hat{p}_{t}^{*}+\hat{s}_{t}-\hat{p}_{t}\right)+\hat{c}_{t}^{*}\right] \\
& +(1-n)(1-z)\left[(1-\lambda)\left(\hat{p}_{h f t}-\hat{s}_{t}-\hat{p}_{h t}^{*}\right)+(1-\theta)\left(\hat{p}_{h t}^{*}-\hat{p}_{t}^{*}\right)+\left(\hat{p}_{t}^{*}+\hat{s}_{t}-\hat{p}_{t}\right)+\hat{c}_{t}^{*}\right]
\end{aligned}
$$

Linearizing the employment conditions for the fixed and flexible wage sectors gives 


$$
\begin{aligned}
& \hat{l}_{t}^{a}=-\omega\left(\hat{w}_{t}^{a}-\hat{w}_{t}\right)+n\left[-\theta\left(\hat{p}_{h t}-\hat{p}_{t}\right)+\hat{c}_{t}\right]+ \\
& (1-n)\left[z\left(-\lambda\left(\hat{p}_{h f t}^{*}-\hat{p}_{h t}^{*}\right)-\theta\left(\hat{p}_{h t}^{*}-\hat{p}_{t}^{*}\right)\right)+(1-z)\left(-\lambda\left(\hat{p}_{h f t}-\hat{s}_{t}-\hat{p}_{h t}^{*}\right)-\theta\left(\hat{p}_{h t}^{*}-\hat{p}_{t}^{*}\right)\right)+\hat{c}_{t}^{*}\right] \\
& \hat{l}_{t}^{f}=-\omega\left(\hat{w}_{t}^{f}-\hat{w}_{t}\right)+n\left[-\theta\left(\hat{p}_{h t}-\hat{p}_{t}\right)+\hat{c}_{t}\right]+ \\
& (1-n)\left[z\left(-\lambda\left(\hat{p}_{h f t}^{*}-\hat{p}_{h t}^{*}\right)-\theta\left(\hat{p}_{h t}^{*}-\hat{p}_{t}^{*}\right)\right)+(1-z)\left(-\lambda\left(\hat{p}_{h f t}-\hat{s}_{t}-\hat{p}_{h t}^{*}\right)-\theta\left(\hat{p}_{h t}^{*}-\hat{p}_{t}^{*}\right)\right)+\hat{c}_{t}^{*}\right] \\
& \hat{l}_{t}^{* a}=-\omega\left(\hat{w}_{t}^{* a}-\hat{w}_{t}^{*}\right)+(1-n)\left[-\theta\left(\hat{p}_{f t}^{*}-\hat{p}_{t}^{*}\right)+\hat{c}_{t}^{*}\right]+ \\
& (1-n)\left[z^{*}\left(-\lambda\left(\hat{p}_{f h t}-\hat{p}_{f t}\right)-\theta\left(\hat{p}_{f t}-\hat{p}_{t}\right)\right)+\left(1-z^{*}\right)\left(-\lambda\left(\hat{p}_{f h t}^{*}+\hat{s}_{t}-\hat{p}_{f t}\right)-\theta\left(\hat{p}_{f t}-\hat{p}_{t}\right)\right)+\hat{c}_{t}\right] \\
& \hat{l}_{t}^{* f}=-\omega\left(\hat{w}_{t}^{* f}-\hat{w}_{t}^{*}\right)+(1-n)\left[-\theta\left(\hat{p}_{f t}^{*}-\hat{p}_{t}^{*}\right)+\hat{c}_{t}^{*}\right]+ \\
& (1-n)\left[z^{*}\left(-\lambda\left(\hat{p}_{f h t}-\hat{p}_{f t}\right)-\theta\left(\hat{p}_{f t}-\hat{p}_{t}\right)\right)+\left(1-z^{*}\right)\left(-\lambda\left(\hat{p}_{f h t}^{*}+\hat{s}_{t}-\hat{p}_{f t}\right)-\theta\left(\hat{p}_{f t}-\hat{p}_{t}\right)\right)+\hat{c}_{t}\right]
\end{aligned}
$$

Linearizing the implicit labor supply schedules for the fixed and flexible wage setters gives

$$
\begin{aligned}
& \hat{w}_{t}^{a}=\hat{p}_{t}+\rho \hat{c}_{t}+\psi \hat{l}_{t}^{a} \\
& \hat{w}_{t}^{f}=E_{t-1}\left(\hat{p}_{t}+\rho \hat{c}_{t}+\psi \hat{l}_{t}^{f}\right) \\
& \hat{w}_{t}^{* a}=\hat{p}_{t}^{*}+\rho \hat{c}_{t}^{*}+\psi \hat{l}_{t}^{* a} \\
& \hat{w}_{t}^{* f}=E_{t-1}\left(\hat{p}_{t}^{*}+\rho \hat{c}_{t}^{*}+\psi \hat{l}_{t}^{* f}\right)
\end{aligned}
$$

Finally, the linearization of the Euler equation and the money market clearing conditions (using the fact that the nominal interest rate is constant in equilibrium) gives:

$$
\begin{aligned}
& \hat{p}_{t}+\rho \hat{c}_{t}=E_{t}\left(\hat{p}_{t+1}+\rho \hat{c}_{t+1}\right) \\
& \hat{p}_{t}^{*}+\rho \hat{c}_{t}^{*}=E_{t}\left(\hat{p}_{t+1}^{*}+\rho \hat{c}_{t+1}^{*}\right) \\
& \hat{m}_{t}-\hat{p}_{t}=\rho \hat{c}_{t} \\
& \hat{m}_{t}^{*}-\hat{p}_{t}^{*}=\rho \hat{c}_{t}^{*}
\end{aligned}
$$

To get (2.1) of the text, use equations (B19) and (B20), together with (B6) and (B7), using the definition, $x_{t}=\hat{x}_{t}-E_{t-1} \hat{x}_{t}$, noting that for all prices, this variable will be zero, given that prices are set in period $t-1$. 
To get (2.2) of the text, use the balance of payments condition (B8), substituting in the pricing equations, and taking expectations dated $t$ - 1 , gives

$$
E_{t-1}\left(\hat{c}_{t}-\hat{c}_{t}^{*}\right)=(1-\theta) E_{t-1}\left(\hat{w}_{t}-\hat{w}_{t}^{*}-\hat{s}_{t}\right)+\frac{r d \hat{B}_{t}}{(1-n) \bar{P} \bar{C}}
$$

Doing the same for the employment equations, noting that in expected terms (in the linear approximation), employment and wages of both groups will be the same, gives us

$$
E_{t-1}\left(\hat{l}_{t}-\hat{l}_{t}^{*}\right)=-\theta E_{t-1}\left(\hat{w}_{t}-\hat{w}_{t}^{*}-\hat{s}_{t}\right)
$$

Finally, from the labor supply equations, we have

$$
E_{t-1}\left(\hat{w}_{t}-\hat{w}_{t}^{*}-\hat{s}_{t}\right)=\rho E_{t-1}\left(\hat{c}_{t}-\hat{c}_{t}^{*}\right)+\psi E_{t-1}\left(\hat{l}_{t}-\hat{l}_{t}^{*}\right)
$$

From (B22) and (B23),

$$
E_{t-1}\left(\hat{w}_{t}-\hat{w}_{t}^{*}-\hat{s}_{t}\right)=\frac{\rho}{(1+\psi \theta)} E_{t-1}\left(\hat{c}_{t}-\hat{c}_{t}^{*}\right),
$$

Combining (B21) and (B24), and updating to period $t$ (and using the fact that $E_{t-1} d \hat{B}_{t+1}=d \hat{B}_{t}$ ) gives (2.2) of the text.

Now take the balance of payments equation (B8) again, substituting in for prices, and take away date $t-1$ expectations (i.e. use the definition $x_{t}=\hat{x}_{t}-E_{t-1} \hat{x}_{t}$ again), gives (2.3) of the text.

To get (2.5) of the text, use equations (B17) and (B18), substitute in for the price definitions, and take away date $t-1$ expectations. 


\section{Table 1(a) Optimal conditions for consumer and firm}

\begin{tabular}{ll|l} 
Euler equation: $\quad \frac{C_{t}^{-\rho}}{P_{t}}=\beta\left(1+r_{t+1}\right) E_{t} \frac{C_{t+1}^{-\rho}}{P_{t+1}} \quad$ Home Price: $\quad P_{h t}=\frac{\lambda}{\lambda-1} \frac{E_{t-1}\left(d_{t-1} C_{h t} W_{t}\right)}{E_{t-1}\left(d_{t-1} C_{h t}\right)}$
\end{tabular}

Money demand: $\frac{M_{t}}{P_{t}}=\chi C_{t}^{\rho} \frac{1+r_{t+1}}{r_{t+1}}$

PCP Price: $\quad P_{h f t}=\frac{\lambda}{\lambda-1} \frac{E_{t-1}\left(Z_{t} S_{t}^{\lambda} W_{t}\right)}{E_{t-1}\left(Z_{t} S_{t}^{\lambda}\right)}$

Flexible wage: $W_{t}^{a}=\frac{\omega \eta}{\omega-1} P_{t} C_{t}^{\rho} L_{t}^{a \psi}$

LCP Price: $\quad P_{h f t}^{*}=\frac{\lambda}{\lambda-1} \frac{E_{t-1}\left(Z_{t} W_{t}\right)}{E_{t-1}\left(Z_{t} S_{t}\right)}$

Fixed wage: $\quad W_{t}^{f}=\frac{\omega \eta}{\omega-1} \frac{E_{t-1}\left(L_{t}^{f(1+\psi)}\right)}{E_{t-1}\left(\frac{L_{t}^{f}}{P_{t} C_{t}^{\rho}}\right)}$

Definition: $\quad Z_{t}=d_{t-1} P_{h t}^{*(\lambda-\theta)} P_{t}^{* \theta} C_{t}^{*}$

Table 1 (b) Price and Wage Index

\begin{tabular}{l|l} 
Wage index: $W_{t}=\left(v\left(W_{t}^{a}\right)^{1-\omega}+(1-v)\left(W_{t}^{f}\right)^{1-\omega}\right)^{\frac{1}{1-\omega}}$ & CPI: $\quad P_{t}=\left(n P_{h t}^{1-\theta}+(1-n) P_{f t}^{1-\theta}\right)^{\frac{1}{1-\theta}}$
\end{tabular}

Import Price Index: $P_{f t}=\left[\left(1-z^{*}\right)\left(S P_{f h t}^{*}\right)^{1-\lambda}+z^{*} P_{f h t}^{1-\lambda}\right]^{\frac{1}{1-\lambda}}$

Table1 (c) Market Equilibrium

Employment (flex wage): $L_{t}^{a}=v\left(\frac{W_{t}^{a}}{W_{t}}\right)^{-\omega}\left[Y_{h t}+(1-z) Y_{h f t}+z Y_{h f t}^{*}\right]$

Employment (fix wage): $L_{t}^{f}=(1-v)\left(\frac{W_{t}^{f}}{W_{t}}\right)^{-\omega}\left[Y_{h t}+(1-z) Y_{h f t}+z Y_{h f t}^{*}\right]$

Home sales: $Y_{h t}=C_{h t}=n\left(\frac{P_{h t}}{P_{t}}\right)^{-\theta} C_{t} \quad$ Foreign sales (PCP): $Y_{h f t}=(1-n)\left(\frac{P_{h f t}}{S_{t} P_{h t}^{*}}\right)^{-\lambda}\left(\frac{P_{h t}^{*}}{P_{t}^{*}}\right)^{-\theta} C_{t}^{*}$

Foreign sales $(\mathrm{LCP}): Y_{h f t}^{*}=(1-n)\left(\frac{P_{h f t}^{*}}{P_{h t}^{*}}\right)^{-\lambda}\left(\frac{P_{h t}^{*}}{P_{t}^{*}}\right)^{-\theta} C_{t}^{*}$

Balance of payments: $\quad P_{t} C_{t}+B_{t+1}=P_{h t} Y_{h t}+(1-z) P_{h f t} Y_{h f t}+z S_{t} P_{h f t}^{*} Y_{h f t}^{*}+\left(1+r_{t}\right) B_{t}$ 
Table 2 Exchange Rate Solutions: special cases

\begin{tabular}{|l|l|l|l|}
\hline$z=z^{*}=0$ & $s_{t}=\frac{\left(m_{t}-m_{t}^{*}\right)\left(1+\frac{\sigma}{r}\right)}{\left(\rho(\theta-1)+\left(1+\frac{\sigma}{r}\right)\right)}$ & $z=z^{*}=1$ & $s_{t}=\frac{\left(m_{t}-m_{t}^{*}\right)\left(1+\frac{\sigma}{r}\right)}{\rho+\frac{\sigma}{r}}$ \\
\hline
\end{tabular}

Table 3

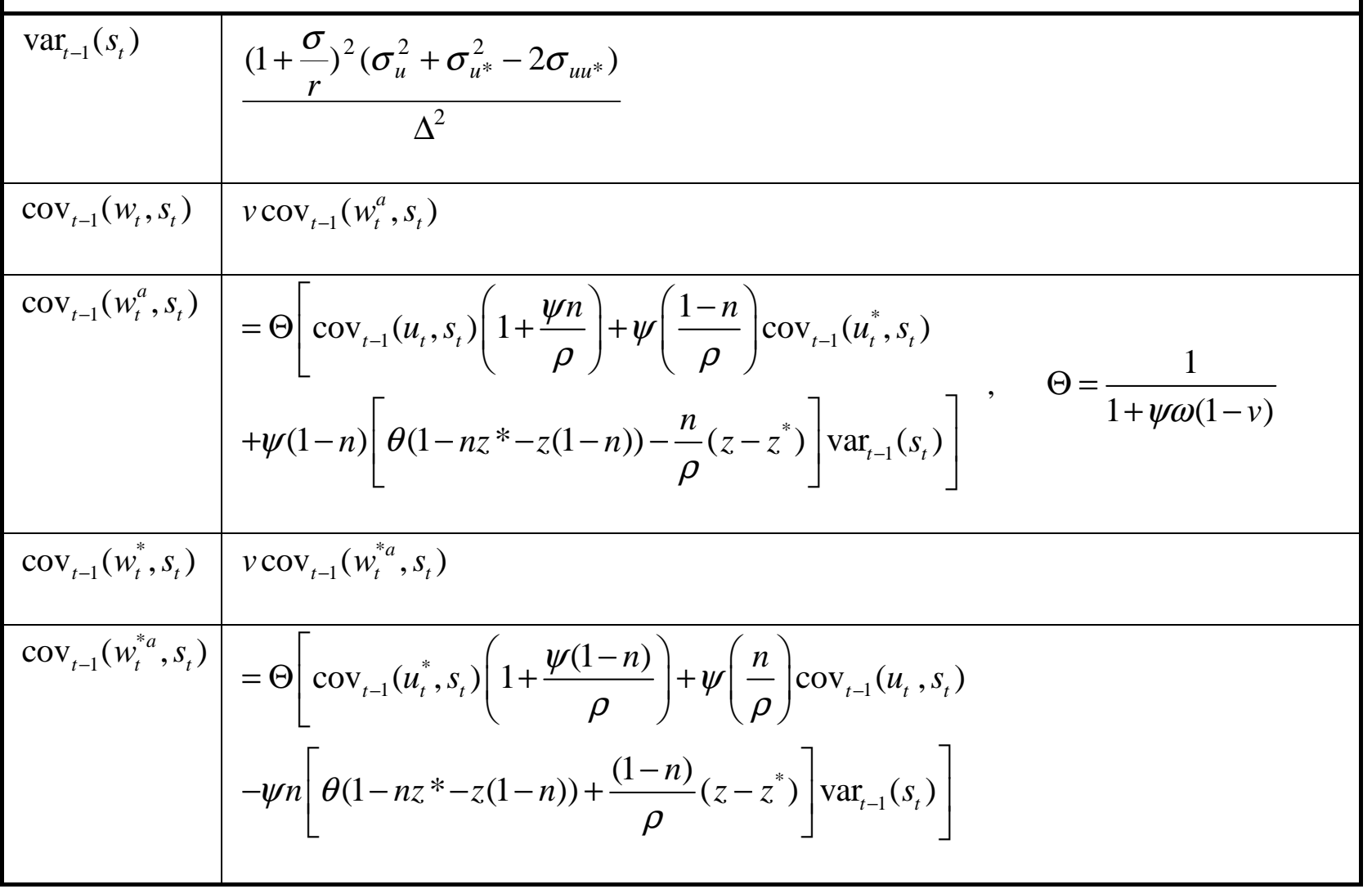

Table 4 Parameter Values

\begin{tabular}{|l|l|l|l|}
\hline$\theta$ & 1.5 & $r$ & 0.1 \\
\hline$\rho$ & 1.25 & $\omega$ & 1.5 \\
\hline$v$ & $0.75 / 0.5$ & $n$ & 0.5 \\
\hline$\psi$ & 1 & & \\
\hline
\end{tabular}



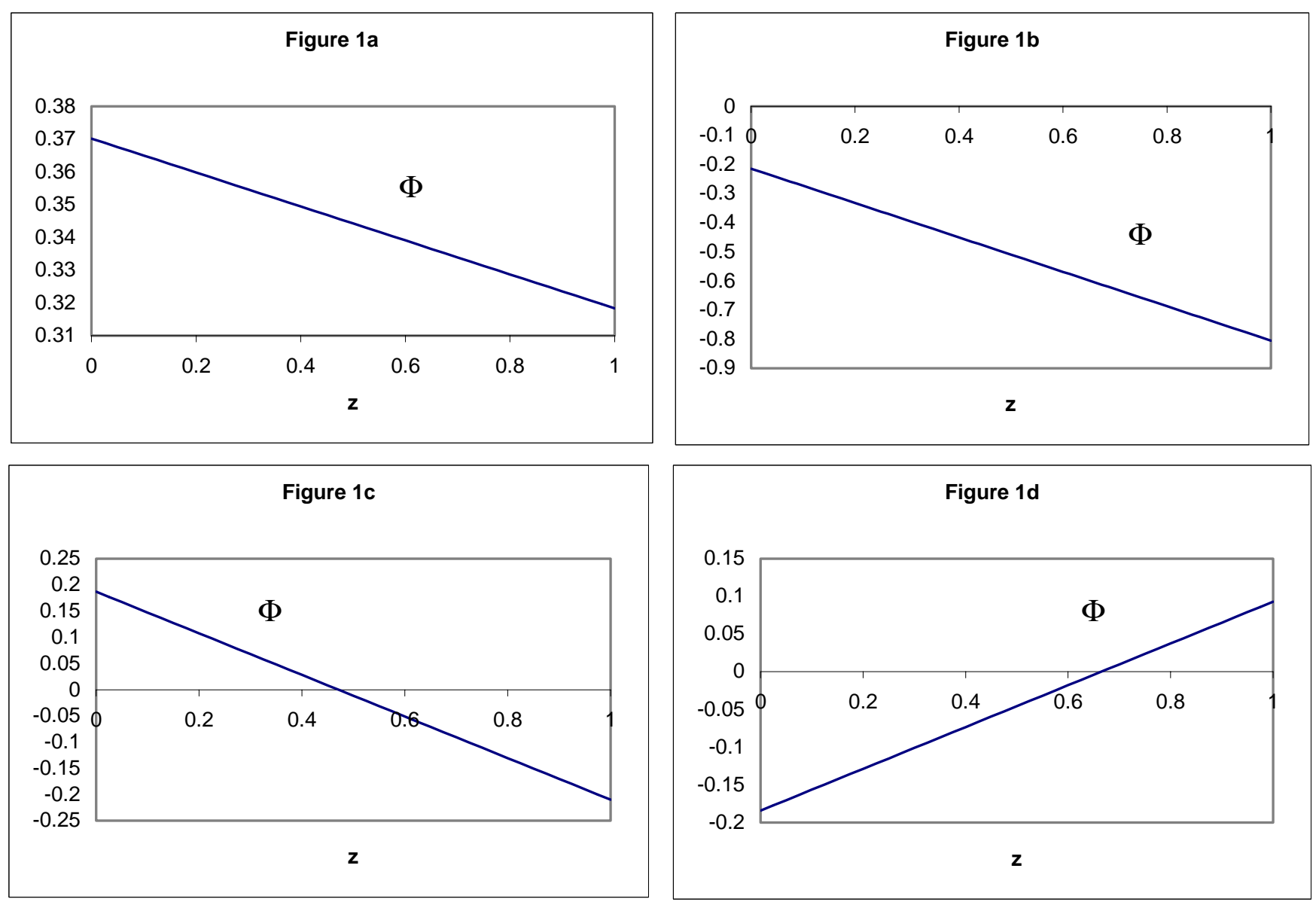

Figure 1

Equilibrium Configurations in the Symmetric Case 


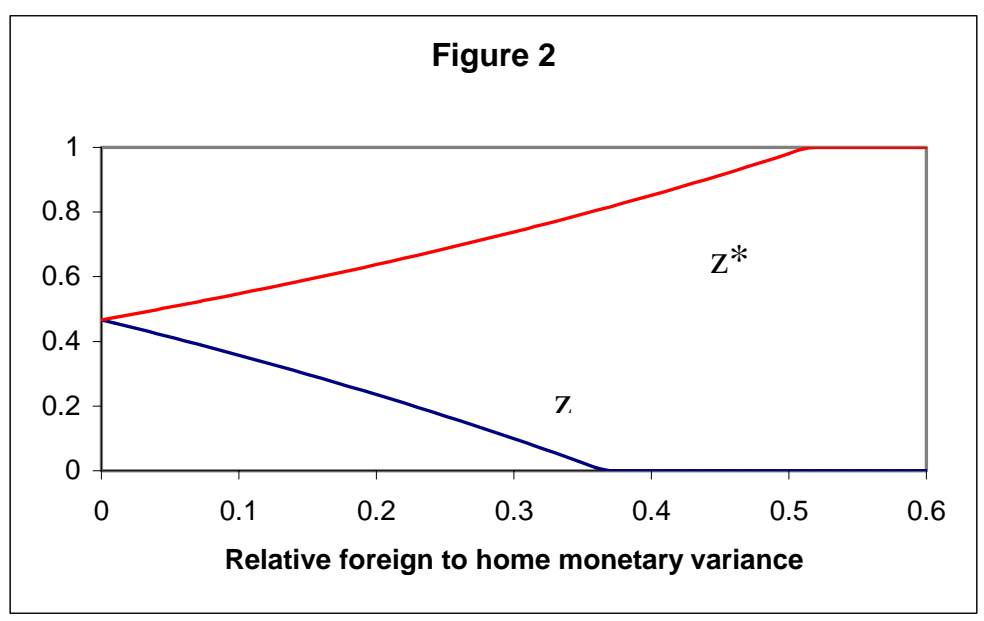

Figure 2

The effect of a reduction in home monetary variance

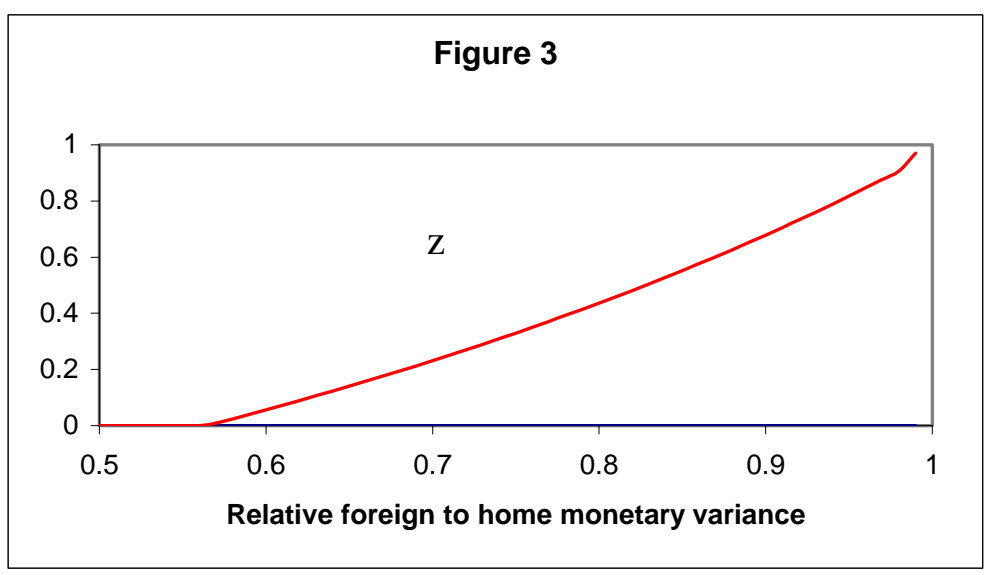

Figure 3

The effect of a reduction in home monetary variance (starting from a PCP equilibrium) 


\section{Mathematical Appendix to \\ "Endogenous Exchange Rate Pass-through When Nominal Prices are Set in Advance" \\ by}

Michael B. Devereux, Charles Engel, and Peter E. Storgaard

\section{The model underlying Table 1}

The structure of the economy is similar to that of Blanchard and Kiyotaki (1987). Within the world economy there is a unit measure of commodities, with each commodity being exclusively produced and sold by a monopolistic competitive firm. At the same time there is a unit measure of households, who consume, save, hold money and work. Households act as monopolists in their work decisions due to the fact that production of each commodity requires differentiated labor inputs. Hence there are two levels of monopoly; at the firm level and at the worker level. We assume that the home economy has both $n$ firms and $n$ households, while the foreign economy has $1-n$ firms and $1-n$ households.

To formally develop the model, we use the following notation for the distribution of events ${ }^{15}$. Say that at any time $t$ event $\vartheta_{t}$ is drawn from a finite number of possible events. The history of all events up to and including that at time $t$ is denoted $\vartheta^{t}=\left\{\vartheta_{t}, \vartheta_{t-1}, \vartheta_{t-2}, \ldots\right\}$, which occurs with date zero probability equal to $\pi\left(\vartheta^{t}\right)$.

\section{Households}

Households have utility functions given as in section 2 of the text. The overall consumption index for household $k$ is

$$
C\left(k, \vartheta^{t}\right)=\left[n^{1 / \theta} C_{h}\left(k, \vartheta^{t}\right)^{\theta-1 / \theta}+(1-n)^{1 / \theta} C_{f}\left(k, \vartheta^{t}\right)^{\theta-1 / \theta}\right]^{\theta / \theta-1}
$$

where the indexes of consumption of home and foreign goods are given by:

$$
\begin{aligned}
& C_{h}\left(k, \vartheta^{t}\right)=\left[n^{-1 / \lambda} \int_{0}^{n} C_{h}\left(i, k, \vartheta^{t}\right)^{\lambda-1 / \lambda} d i\right]^{\lambda / \lambda-1} ; \\
& C_{f}\left(k, \vartheta^{t}\right)=\left[(1-n)^{-1 / \lambda} \int_{n}^{1} C_{f}\left(i, k, \vartheta^{t}\right)^{\lambda-1 / \lambda} d i\right]^{\lambda / \lambda-1} .
\end{aligned}
$$

The consumer price index is given by $P\left(\vartheta^{t}\right)=\left(n P_{h}\left(\vartheta^{t-1}\right)^{1-\theta}+(1-n) P_{f}\left(\vartheta^{t}\right)^{1-\theta}\right)^{\frac{1}{1-\theta}}$, with the

home and foreign good price indexes being defined as $P_{h}\left(\vartheta^{t-1}\right)=\left[\frac{1}{n} \int_{0}^{n} P_{h}\left(i, \vartheta^{t-1}\right)^{1-\lambda} d i\right]^{1 / 1-\lambda}$

and $P_{f}\left(\vartheta^{t}\right)=\left[\frac{1}{1-n} \int_{n}^{n+\left(1-z^{*}\right)(1-n)} S_{t}\left(\vartheta^{t}\right)^{1-\lambda} P_{f h}^{*}\left(i, \vartheta^{t-1}\right)^{1-\lambda} d i+\frac{1}{1-n} \int_{n+\left(1-z^{*}\right)(1-n)}^{1} P_{f h}\left(i, \vartheta^{t-1}\right)^{1-\lambda} d i\right]^{\frac{1}{1-\lambda}}$ respecti

\footnotetext{
${ }^{15}$ To simplify and shorten the presentation of the paper, this state-contingent notation is omitted in the text.
} 
vely. In this notation $P_{f h}\left(i, \vartheta^{t-1}\right)$ represents the home currency price of good $i$ which is produced in the foreign country and sold in the home country, and $P_{f h}^{*}\left(i, \vartheta^{t-1}\right)$ is the foreign currency price of foreign good $i$ sold in the home country.

Households choose a pattern of consumption across the different types of goods, choose how much money to hold, how much to save and in what different types of assets, and set their wages, subject to the demand for labor they are faced with. In terms of wage setting, households are of two types. Type $a$, 'wage-adjusters' choose their wages ex-post, after the money shocks have been realized for the period. Type $f$, 'wage fixers' choose wages ex-ante, before money shocks have been realized. We allow for full risk sharing at the domestic level, so that Type $a$ and Type $f$ wage setters can diversify away the specific risk associated with their different expost wage incomes. As we see below, this will ensure that consumption of the two types is in constant proportion. With a slight additional assumption, we can ensure that consumption is identical across types.

To illustrate the household's problem, we write the budget constraint for type $a$ household $k$ as follows

$$
\begin{aligned}
& P\left(\vartheta^{t}\right) C\left(k, \vartheta^{t}\right)+M\left(k, \vartheta^{t}\right)+B\left(k, \vartheta^{t}\right)+\sum d\left(\vartheta^{t+1}\right) x\left(k, \vartheta^{t+1}\right)= \\
& W\left(k, \vartheta^{t}\right) H\left(k, \vartheta^{t}\right)+\Pi\left(k, \vartheta^{t}\right)+\left(1+r\left(\vartheta^{t-1}\right)\right) B\left(k, \vartheta^{t-1}\right)+M\left(k, \vartheta^{t-1}\right)+T\left(\vartheta^{t}\right)+x\left(k, \vartheta^{t}\right)
\end{aligned}
$$

The household consumes, accumulates money balances, purchases international bonds and statecontingent domestic bonds (which may only be traded within the domestic economy). Income is received from wage income, profit income, interest on international bonds, money held over from last period, transfers from the monetary authority, and state-contingent domestic bond payouts from other home residents. Household $k$ sets its wage given its local monopoly (see below), so implicitly employment is a function of the wage, i.e. $H\left(k, \vartheta^{t}\right)=\tilde{H}\left(k, \vartheta^{t}, W\left(k, \vartheta^{t}\right)\right)$. 
Since this is a type $a$ household, the wage is set at time $t$ and therefore is conditioned on $\vartheta^{t}$. For a household $k$ of type $f$, we denote the wage as $W\left(k, \vartheta^{t-1}\right)$.

Household $k$ maximizes utility subject to the budget constraint (A1). We may write the Euler equations governing the choice of international bonds, state contingent domestic assets, and the optimal choice of money holdings and the wage as follows.

$$
\begin{aligned}
& \frac{C\left(k, \vartheta^{t}\right)^{-\rho}}{P\left(\vartheta^{t}\right)}=\beta\left(1+r\left(\vartheta^{t}\right)\right) \sum \pi\left(\vartheta^{t+1}\right) \frac{C\left(k, \vartheta^{t+1}\right)^{-\rho}}{P\left(\vartheta^{t+1}\right)} \\
& d\left(\vartheta^{t+1}\right) C\left(k, \vartheta^{t}\right)^{-\rho}=\beta \pi\left(\vartheta^{t+1}\right) C\left(k, \vartheta^{t+1}\right)^{-\rho} \\
& \frac{M\left(k, \vartheta^{t}\right)}{P\left(\vartheta^{t}\right)}=\chi C\left(k, \vartheta^{t}\right)^{\rho} \frac{1+r\left(\vartheta^{t}\right)}{r\left(\vartheta^{t}\right)} \\
& W\left(k, \vartheta^{t}\right)=\frac{\eta \omega}{\omega-1} P\left(\vartheta^{t}\right) C\left(k, \vartheta^{t}\right)^{\rho} H\left(k, \vartheta^{t}\right)^{\psi}
\end{aligned}
$$

Conditions (A2) and (A3) are straightforward. Condition (A4) represents the 'money demand schedule', while condition (A5) represents the optimal wage. In this condition, we assume (as is confirmed below) that the individual wage setters face a constant elasticity of demand for their labor, with elasticity $\omega$. Hence the wage that monopoly workers set is equal to a markup over their marginal rate of substitution between nominal consumption and leisure.

Given aggregate consumption defined as a solution to this problem, it is easy to use the standard rules of two stage budgeting to establish that the household $k$ 's demand for home good $i$ is given by

$$
C\left(k, i, \vartheta^{t}\right)=\left(\frac{P_{h}\left(i, \vartheta^{t-1}\right)}{P_{h}\left(\vartheta^{t-1}\right)}\right)^{-\lambda}\left(\frac{P_{h}\left(\vartheta^{t-1}\right)}{P\left(\vartheta^{t}\right)}\right)^{-\theta} C\left(k, \vartheta^{t}\right)
$$

Likewise, the household's demands for foreign PCP and LCP goods are, respectively: 


$$
\begin{aligned}
& C\left(k, i, \vartheta^{t}\right)=\left(\frac{P_{f h}^{*}\left(i, \vartheta^{t-1}\right)}{S\left(\vartheta^{t}\right) P_{f}\left(\vartheta^{t}\right)}\right)^{-\lambda}\left(\frac{P_{f}\left(\vartheta^{t}\right)}{P\left(\vartheta^{t}\right)}\right)^{-\theta} C\left(k, \vartheta^{t}\right) \\
& C\left(k, i, \vartheta^{t}\right)=\left(\frac{P_{f h}\left(i, \vartheta^{t-1}\right)}{P_{f}\left(\vartheta^{t}\right)}\right)^{-\lambda}\left(\frac{P_{f}\left(\vartheta^{t}\right)}{P\left(\vartheta^{t}\right)}\right)^{-\theta} C\left(k, \vartheta^{t}\right) .
\end{aligned}
$$

For type $f$ wage setters, the wage is set based on the information set $\vartheta^{t-1}$. But if the wage setters also maximize utility subject to their expected labor demand schedule, then for type $f$ wage setters we may replace (A5) by

$$
W\left(k, \vartheta^{t-1}\right)=\frac{\eta \omega}{\omega-1} \frac{\sum \pi\left(\vartheta^{t}\right) H\left(k, \vartheta^{t}\right)^{1+\psi}}{\sum \pi\left(\vartheta^{t}\right) \frac{H\left(k, \vartheta^{t}\right)}{P\left(\vartheta^{t}\right) C\left(k, \vartheta^{t}\right)^{\rho}}} .
$$

Since all individuals of type $a$ have identical outcomes for employment and wages, they have identical consumption. The same holds for all type $f$ agents. Type $a$ and type $f$ residents will have different wages and ex post employment outcomes. But because there is a complete market in state-contingent assets among home country residents, and there is additive separability in preferences, the consumption of type $a$ and type $f$ residents will be equalized up to a constant factor of proportionality, related to ex-ante differences in wealth, due to their differences in ability to set wages. It is convenient to go slightly beyond this and to assume that consumption rates are equalized. This avoids the added notation of having to account for the differences in type $a$ and type $f$ consumption in the model presentation in Table 1. Because the consumption rates are in constant proportion, it makes no difference at all to the solutions using the linear approximations in section 3 of the paper. From a modeling perspective, one way to ensure that consumption of both types is equalized is to imagine that type $a$ and type $f$ are drawn from a distribution with probability $\mathrm{v}$ and $1-\mathrm{v}$ respectively, and that in every period, the market in state contingent assets for the next period must close before agents know which type they are. This 
will ensure that they are ex ante identical in every period, and hence, with full state contingent assets, also ex post identical in terms of consumption.

\section{Firms}

Firms are owned by domestic households, and rebate all profit back to households. Thus, they will use the household's nominal state discount factor $d\left(\vartheta^{t}\right)$ in order to evaluate their profits, when choosing prices in period $t-1$ to apply for period $t$. First we note that for any event $\vartheta^{t}$, a firm $i$ will choose its employment of differentiated labor to minimize wage costs

$$
\begin{aligned}
& \int_{0}^{n} W\left(k, \vartheta^{t}\right) L\left(k, i, \vartheta^{t}\right) d k \text {, given any output target. From this, the firm's cost function is } \\
& \left(\frac{1}{n} \int_{0}^{n} W\left(k, \vartheta^{t}\right)^{1-\omega}\right)^{\frac{1}{1-\omega}} Y\left(i, \vartheta^{t}\right) \equiv M C\left(\vartheta^{t}\right) Y\left(i, \vartheta^{t}\right) \text {. This affirms our assumption that an individual }
\end{aligned}
$$

worker $k$ will face a labor demand schedule for her specialist services that has a constant elasticity $\omega$.

In choosing prices in advance the firm will take into account the demand schedules of home and foreign consumers. We assume that firms can perfectly price discriminate across countries. As a result, it may set a separate price for home and foreign markets. The objective function of the home firm choosing its price for sales in the home market will be $\sum d\left(\vartheta^{t}\right)\left[P\left(i, \vartheta^{t-1}\right)-M C\left(\vartheta^{t}\right)\right] C_{h}\left(i, \vartheta^{t}\right)$, where the demand schedule for firm $i$ selling in the home market is defined in Table 1(c). The firm faces a constant elasticity of demand $\lambda$, and given its demand function, it will choose a price equal to

$$
P_{h}\left(i, \vartheta^{t-1}\right)=\frac{\lambda}{\lambda-1} \frac{\sum d\left(\vartheta^{t}\right) C_{h}\left(i, \vartheta^{t}\right) M C\left(\vartheta^{t}\right)}{\sum d\left(\vartheta^{t}\right) C_{h}\left(i, \vartheta^{t}\right)}
$$

In a parallel manner, the firm selling to the foreign market will choose a price to maximize state contingent profits, and will face the demand schedules given by either $Y_{h f t}$ or $Y_{h f t}^{*}$, depending on 
whether it follows a PCP or LCP rule for setting its price. Again it is easy to establish that the optimal price is represented by the expressions in the right hand panels of Table 1(a). To cut down on excessive notation, and without introducing any ambiguity, we omit the state notation in Table 1, and write the Euler equations and pricing equations in terms of conditional expectations instead. In addition, Table 1 imposes symmetry among firms in each category, and replaces the marginal cost expression with the domestic nominal wage, given in Table 1 (b). 